\title{
Factors affecting $\mathrm{CO}_{2}$ emissions in Top Countries on Renewable Energies: A LMDI decomposition application
}

\author{
Victor Moutinho1,a, Mara Madaleno $^{1, b}$, Roula Inglesi-Lotz ${ }^{2, c}$, Eyup Dogan ${ }^{3, d}$ \\ ${ }^{1}$ GOVCOPP - Research Unit in Governance, Competitiveness and Public Policy, and Department of \\ Economics, Management, Industrial Engineering and Tourism (DEGEIT), University of Aveiro, \\ Campus de Santiago, 3810-193, Aveiro, Portugal \\ aemail: vmoutinho@ua.pt

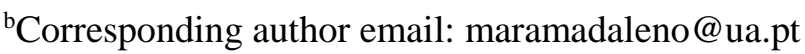 \\ ${ }^{2}$ Department of Economics, University of Pretoria, South Africa \\ c roula.inglesi-lotz@up.ac.za \\ ${ }^{3}$ Department of Economics, Abdullah Gul University, Turkey \\ deyup.dogan@agu.edu.tr
}

\begin{abstract}
This study breaks down carbon emissions into six effects considering the current Top 23 countries group on renewable energies, afterwards divided into two different groups (the TOP countries in Europe and the remaining group entering into the Top 23 countries included in the category Rest of the World). It analyses the effects evolution using a larger available data span that runs from 1985 until 2011, to determine which of the effects had more impact over changes of $\mathrm{CO}_{2}$ emissions. The complete additive decomposition technique was used to examine carbon dioxide $\left(\mathrm{CO}_{2}\right)$ emissions and its components. Moreover, it is performed a comparative analysis to contrast their performance, and a decoupling analysis is presented. For the 1985-2011 period results point for different positive and negative impacts in the behavioral change of $\mathrm{CO}_{2}$ emissions throughout Europe as compared to the Rest of the World. Moreover, the productivity of renewable sources and the financial development effect in renewable electricity generation per GDP are the main responsible for the total and negative changes of $\mathrm{CO}_{2}$ emissions in the last decade; whereas an increase in total changes of emissions are observed due to the fossil fuel energy consumption effect. The multiplicative cross effect, into these two important effects in $\mathrm{CO}_{2}$ emissions decomposed, indicate an aggregate proxy effect of the energy technology level of a country's economy.
\end{abstract}

Keywords: decomposition; emissions; renewable energy; LMDI; Renewable Energy Country Attractiveness Index

JEL codes: Q42, Q51, Q56 


\section{Introduction}

Climate change and global warming are among the main concerns for all nations globally. The environmental consequences of increasing greenhouse gas emissions, and particularly carbon dioxide $\left(\mathrm{CO}_{2}\right)$, have started becoming visible not only in the temperature levels of the planet but also, due to changing weather conditions that consequently affect the nation's economy. Stakeholders, policy makers, researchers and organizations search for technologies, programs and policies to assist them with the goal of emissions reduction and mitigation. On the demand-side, energy efficiency improvements are proposed way forward. This is to ensure reducing energy requirements of countries or to ensure they consume energy less intensively. From a supply side point of view, the most effective solution is to combine environmental concerns with worries on the scarcity of natural resources. For that it should be considered the substitution of fossil fuel-based energy generation with renewable and cleaner energy sources alternatives.

The European 2020 strategy has settled three goals (the "20-20-20" targets) for climate and energy policy to be reached (reducing at least 20\% of GHG emissions as compared to 1990 levels, increase to $20 \%$ the renewable energy share in final energy consumption and increase energy efficiency by 20\%). According to the European Commission (2014), the strategy points out that the EU is committed to take a decision to move to a $30 \%$ reduction by 2020 as compared to 1990 levels. Climate and energy policies despite considering a transition towards a low carbon economy preventing the inevitable catastrophic climate change also contribute to the European 2020 strategies core goals of enabling sustainable growth. The key pedals for emissions reduction, renewable energies and energy efficiency, can promote innovation and create jobs [1].

With a low carbon economy we could generate wider socioeconomic benefits given that energy dependence is reduced. Moreover, there is the replacement of parts of fossil fuel imports with domestic resources, helping to reduce air pollution and associated health risks. Furthermore, it lowers health costs while increasing socioeconomic well-being. In current reality, the use of energy is by far the largest source of emissions and its $\mathrm{CO}_{2}$ emissions dominate total GHG emissions in about three quarters. Summing up, increasing demand comes from economic growth and development worldwide, where energy demand from fossil fuels plays a key role in the upward trend in $\mathrm{CO}_{2}$ emissions. In this "game" there are countries which are placed at the forefront and others that remain very distant from their goal targets in the world replacement of a nonpolluting environment. 
Provided the relevance and applicability of renewables in energy production in a way to mitigate carbon emissions, from a selected sample of countries ranked in accordance to the Renewable Energy Country Attractiveness Index (RECAI) ${ }^{1}$, this article major contribution is to consider in the Log-Mean Divisia Index (LDMI) model decomposition including the following factors: carbon intensity, the use of renewable resources resulting from trade openness, non-renewable resources intensity, renewable resources productivity and the effect of financial credit capacity to promote renewables usage in energy production. In this article we try to stretch answers to the following relevant and unexplored questions: i) from the numbered factors in carbon emissions mitigations which are the most relevant?; ii) given the selected sample, are there different impacts of explanatory effects among European countries and countries outside Europe?; iii) from the most important factors, in which country inside each group existed higher explanatory power to mitigate changes in emissions? It is considered that the answers to these questions here provided will be a useful instrument for energy policy decision makers and to other players/decision makers that act in energy markets.

The RECAI index ranks countries internationally based on their renewable energy adoption using various factors such as the political support for renewables, affordability of renewables in their region, infrastructure, technology potentials and others. The top 23 of these countries (at least those that have been ranked high in their renewable energy attractiveness) have embraced the renewable energy potentials and hence, it would be expected their emissions to show a decreasing trend ${ }^{2}$. With these countries selection, this work allows us to unfold the driving forces of emissions changes in two distinct groups of countries. . These results will be important not only for policy makers in countries with high contributions of renewable energies in their supply mix, but also to the rest of the countries, which could learn what their future path might be with the adoption of renewable energies. By identifying and understanding the importance of the factors and their contribution's magnitude, policy makers can select the most appropriate policies to reduce $\mathrm{CO}_{2}$ emissions [2].

\footnotetext{
${ }^{1}$ http://www.ey.com/GL/en/Industries/Power---Utilities/EY-renewable-energy-country-attractivenessindex-our-index.

${ }^{2}$ We have considered the top 23: Australia, Austria, Belgium, Brazil, Canada, Chile, Denmark, France, Indonesia, Italy, Japan, Kenya, Mexico, Netherlands, Norway, Peru, Philippines, Portugal, Spain, Sweden, Turkey, United Kingdom and United States. Note that, in 2014, the top 23 from the Top 40 countries were: US, China, Germany, Japan, UK, Canada, India, Australia, France, South Korea, Italy, Brazil, Belgium, Chile, Denmark, Netherlands, Portugal, Spain, South Africa, Sweden, Taiwan, Thailand and Turkey, in this order, but we were not able to work with all due to data availability issues.
} 
To achieve this goal, this work makes use of the LMDI method to disaggregate changes in $\mathrm{CO}_{2}$ emissions of the top 23 countries listed in RECAI for the period 1985 to 2011 into six factors: carbon trade intensity, fossil fuels trade effect, fossil fuel intensity, renewable source productivity, the financial power of electricity effect and financial development effect.

We contribute to previous research in several different ways. First, following a LMDI approach, the $\mathrm{CO}_{2}$ mitigation is analyzed into two distinct groups and considering a larger data span from 1985 until 2011, allowing us to evaluate the impact of the entry into force of energy emission policies. Second, the LMDI is used to identify the different driving factors of emissions related to energy. This allows explaining the differences into the levels of efficiency among the two distinct groups of countries. Third, it is performed a comparative analysis to contrast their performance, and a decoupling analysis is presented. Finally, we use the entire sample of 23 countries ranked in the top RECAI as a group, and also analyzing them in an individual way within each group to check out for still persistent differences.

The LDMI method allows to decompose changes in $\mathrm{CO}_{2}$ emissions (and intensities) into separate indexes for emissions intensity and other indexes that represent various types of structural factors. It is used to decompose emissions at any level of aggregation into major components, all expressed as indexes relative to a selected base year when combining the intensity indexes. The shares of emissions serve as weights in calculating a weighted average of year-to-year changes in the intensities for the various elements considered to influence emissions. LDMI is an easy formulation which gives perfect decomposition where results do not contain an unexplained residual term, simplifying results interpretation. It is also consistent in aggregation since effects estimates at the sub-group level can be aggregated to provide the corresponding effect at the group level $[3]^{3}$.

The rest of the article develops as follows. Section 2 discusses the literature developments and applications of the LMDI method in the energy literature, with particular focus on other studies dealing with the decomposition of emissions. Section 3 explains the methodology adopted in this paper and section 4 presents the empirical results. Finally, section 5 summarizes the study and provides some policy implications and a general discussion of the attained results.

\section{Literature Review}

\footnotetext{
${ }^{3}$ [3] provides a practical guide useful to all that wish to implement the method.
} 
As [4] explain, in the past, primarily econometric and multivariate techniques were used to examine the factors behind the trends of economic, environmental, and social indicators. "However, their main objective is to reduce the attribute space of a large number of variables to a smaller one for indicating the most influential factors" ([4]: p. 4160). The decomposition techniques provide a different approach to study the complexity of the reality. The purpose of this type of analysis is to disaggregate an indicator in quantifiable factors, ceteris paribus. Interactions between factors are not detected but their relative change contributions over time can be revealed, in an effort to inform about policies to be pursued and measures to be adopted.

In the energy literature, the decomposition techniques have been a particularly suitable and convenient tool over the last two decades in order to decouple the determinants of various indicators such as energy consumption and efficiency ([5]; [6]; [7]; [8]; [9]; [10]; [11]; [12]; [13]; [2]; [14]; [15]) and carbon emissions ([16]; [17]; [18]; [19]; [20]; [1]; [22]; [23]; [24]; $[25] ;[26])$.

Studying and applying LMDI decompositions in Europe, [27] conclude that changes in the economy structure are predominant drivers of energy intensity in the economy, using a sample of EU 15 countries between 1991 and 2005. They even suggest that an economy restructuring towards services would not be likely to lead to an improvement in the energy efficiency component due to heterogeneity and lack of international competition. For the sample of EU 27, [28] reported that the structural effect together with the activity effect were able to offset the positive intensity effect. Together they lead to energy consumption growth of $2.25 \%$ in the 2001-2008 period. Afterwards, [29] used detailed data of activity sectors for 20 selected EU countries reinforcing their previous conclusion and marking the industry sector as the prime energy efficiency improvement mover. They provide special credit to energy efficiency improvement in post-communist countries [30].

In 2015, [30] used the LMDI decomposition technique to analyze energy consumption using three different levels of data aggregation for the complete sample of EU28 countries in the pre-crisis period of (2004-2008) and the crisis period (2008-2012). The authors conclude that the recent decline in energy consumption is mainly caused by economic slowdown provided that improvements in energy intensity in the EU 28 seem to be slowing. They observe that the intensity effect was the major factor influencing energy consumption, whereas that of the activity sector (representing the economy overall performance) was less 
important. Moreover, the structural effect impact was also of minor magnitude, with higher evidenced impact on periods of oil price surges than in periods of high oil prices.

The decomposition techniques also are employed in the literature to examine the determinants of $\mathrm{CO}_{2}$ emissions of various countries. For example, [31] also demonstrated the ability of LMDI method to examine differences over time analyzing the driving forces of $\mathrm{CO}_{2}$ from the power sector for the EU. By using the traditional LMDI approach, [3] not only examined the factors affecting the emissions in five European Union countries for the period 2000-2011 but by dividing the time sample in two, they managed to show the differences in the factors' impact's magnitude before and during a financial crisis. They found that economic growth and resource intensity are factors opposite to each other and that counterbalance each other.

Other of the other hand, in others countries of the Rest of the world, for example, [25] examined the driving forces of $\mathrm{CO}_{2}$ emissions in Philippines from 1991 to 2014, making use of the LMDI model. Their findings showed that economic growth and higher living standards are negative contributors to $\mathrm{CO}_{2}$ emissions (left-hand side of an Environmental Kuznets Curve EKC) and that inconsistent energy structures are damaging elements to the emissions performance of Philippines. [26] agreed with the findings on economic growth in their study looking at the factors of emissions in various provinces and municipalities in China; while the energy intensity's effect is found to vary depending on the geographic regions, it is also found that the energy structure has little influence on emissions changes.

The emissions decomposition literature used primarily conventional factors such as the energy intensity, economic production and the structure of the economy to determine the change in emissions over the years ([32], [33], [34]). As [35] explain "These macroeconomic factors do have significant effects on $\mathrm{CO}_{2}$ emissions, but they are unable to uncover industrial enterprises' microeconomic behaviors on emission reduction". Moreover, they do not control for specific characteristics in the energy supply mix of the country or other socioeconomic indicators. For example, [36] and [37] both found that investment is a positive contributor to the level of $\mathrm{CO}_{2}$ emissions in China. They state that improving capital productivity and investment directed to green activities would help towards the reduction of emissions. Reference [24] used the LMDI model to disaggregate the emissions in Shanghai, China, into traditional factors such as economic activity and energy intensity. In addition, they extended the model by incorporating microeconomic effects of investment as well as Research and Development (R\&D) behaviors. They concluded, among others, that the 
impact of energy intensity to emission reduction is less than expected (rebound effect) but the adoption of renewable energy sources intensifies its alleviation effect.

Another interesting potential determinant of the emissions level used in [38] is urbanization of a country. In their paper, [38] decomposed the residential direct carbon emissions in China into various household-related factors, using the decomposition approach, with urbanization among them. The main determinants towards increasing emissions were found to be the household income as well as the number of households in the economy. The urbanization level also contributed to the increase in emissions.

In recent studies, researchers combine the level of emissions with other indicators to account for factors such as economic production or value added. So, the carbon intensity (emissions divided by economic output) has attracted some attention in the literature recently ([39], [40]). In [35], while decomposing specifically the industrial carbon intensity of China into various factors, the authors found that investment intensity is the main positive contributor to carbon intensity while $R \& D$ and energy intensity are strong forces towards the reduction of emissions.

Another perspective of $\mathrm{CO}_{2}$ emission levels calls for further examination of the inequality in emissions. Reference [41], for example, looked at the $\mathrm{CO}_{2}$ emission Gini coefficient in China and its determinants. So, they find that the Gini coefficient of emissions is higher for the residential sector than the production sector but more importantly, that the impacts of this inequality of emissions depend highly on the type of energy used.

The energy literature, although somehow more limited, used the decomposition techniques to evaluate the driving forces of emissions for countries in the rest of the world (nonEuropean ones). A structural decomposition method was employed in [42] to disaggregate the changes of total greenhouse gas emissions into its determinants in Australia. Efficiency as well as changes in the production structure of the country was found to "direct" the changes in emissions. A recent study by [43] looking at the changes in the $\mathrm{CO}_{2}$ emissions in Australia for the period 1978 to 2010, used the LMDI method to conclude that improvements in energy efficiency were the main reason for the observed reduction in emissions' intensity, followed by the structural changes of the economy throughout the years (manufacturing towards services sector).

Two studies on the determinants of $\mathrm{CO}_{2}$ emissions in Brazil made use of decomposition techniques: [44] looked at the overall period sample from 1970 to 2009 concluding that 
economic activity and demographic pressure were the main drivers explaining emissions increase; while, they attributed the potential mitigation of emissions to carbon intensity reductions and to the diversification of the energy mix. The second study [45] agreed that carbon intensity and energy mix were the main factors for the trends observed in $\mathrm{CO}_{2}$ emissions, focusing in the shorter period from 2004 to 2009. For the United States, [46] decomposed the $\mathrm{CO}_{2}$ emissions of the country taking into consideration business cycles. They concluded that emissions and their intensity tend to decrease faster in periods of contractions than they increase in periods of expansions; demonstrating thus an asymmetric behavior. For Philippines, [25] notes that there are numerous studies in the energy literature on information about the country's emissions profile, but that there is a lack of analytical studies on the driving forces. They conclude that the contribution of economic activity and energy intensity to $\mathrm{CO}_{2}$ emissions offset each other. For the rest of the non-European countries included in our analysis, no studies dealing with decomposition of emissions (either total or only $\mathrm{CO}_{2}$ ) into their determinants could be identified, to date.

There are also a number of studies that examine the change in emissions of a specific sector or within a comparative framework among various sectors. For example, [47] examined the determinants of emissions particularly in the non-metallic sector by employing the LMDI decomposition technique. According to their results, the structural change plays an important role in the changes in emissions at the aggregate level. Within a regional framework, the Chinese non-metallic industry's emissions result from the transfer of gross output and cement production from developed countries towards emerging economies such as BRICS. The specific level of development, thus, of a country plays a role not only on the level of emissions but also in the significance of factors: the increase in the emissions of the nonmetallic sector in China, India and Brazil, is attributed to fast scale growth, while the reduction in the emissions of US mainly to the scale reduction. Reference [48], for the Korean manufacturing sector, showed that the intensity effect is the primary contributor in the increasing trends of the sector's emissions. The Iron and Steel making industry is examined in [49], while [21] studied the Chinese transport sector's emission characteristics. [50] looked at the potential of the Chinese steel industry to reduce their emissions, while [51] and [52] evaluated the driving factors of carbon emission changes in the chemical industry. For China, [53] combined information within a sectoral dimension and a provincial one. Their results showed that economic output was the main positive contributor to emissions while on the contrary, energy intensity was the main negative contributor. The 
contribution magnitudes of the factors varied among the provinces within the time period of the analysis but not with specific trends among provinces or sectors.

\section{Methodology: Decomposition Model approach}

Our LMDI decomposition approach proposes six factors used to identify, quantify and explain the main determinants of the variation of total energy related $\mathrm{CO}_{2}$ emissions in the 23 top countries listed in the Renewable Energy Country Attractiveness index between 1985 and 2011. The number of countries among the index is selected based on the data availability. We expect the results of the decomposition analysis to show which effects are more crucial to explain changes of $\mathrm{CO}_{2}$ emissions in individual terms and with respect to set contribution. All data has been collected in annual terms.

The six effects included in the decomposition are named as carbon trade intensity (CI), the trade of fossil fuels effect (TF), fossil fuels intensity (FI), renewable sources productivity (RP), electricity financial power effect (EF) and the financial development effect (). By applying the proposed decomposition over total $\mathrm{CO}_{2}$ emissions in these top 23 countries we propose the following decomposition expression in equation (1).

$$
\begin{aligned}
& C O_{2}=\sum_{j=1}^{23} C I_{t, j} \times T F_{t, j} \times F I_{t, j} \times R P_{t, j} \times E F_{t, j} \times F D_{t, j} \\
& =\sum_{j=1}^{23} \frac{C O_{2}}{T O P} \times \frac{T O P}{E N \operatorname{Re} w} \times \frac{E N \operatorname{Re} w}{G D P} \times \frac{G D P}{E \operatorname{Re} w} \times \frac{E \operatorname{Re} w}{F D} \times F D
\end{aligned}
$$

where $\mathrm{CO}_{2}$ represents the energy related $\mathrm{CO}_{2}$ emissions in metric tons of each Top Renewable Energy Country; GDP (total income) means gross domestic product in 2005 US\$; TOP denotes the trade openness measured as the sum of exports and imports of goods and services (as a share of GDP); ERew denotes electricity power derived from renewable sources (wind, solar, geothermal, biomass and waste), measured in kilowatt-hours generated in each of the Top Renewable Energy Countries; ENRew stands for electricity power generated from non-renewable sources (coal, oil and natural gas), being measured in kilowatt-hours in each of the 23 countries; and Fd represents financial development measured as the amount of domestic credit provided to the private sector as a share of GDP. The data on $\mathrm{CO}_{2}$ emissions, GDP, TOP and Fd were obtained from the "World Development Indicators" dataset (http://data.worldbank.org), and the data on ERew and ENRew are taken from "the US Energy Information Administration" dataset (www.eia.gov). 
With respect to the decarbonization effect CO2/ENRew (CO2/TOP x TOP/ENRew), we have considered in the decomposition model an interconnection with the effect trade openness (which may affect energy consumption through the income effect and through the technique effect), such that in the cross product in the decomposition model proposed we will have the explanatory importance of the weight of $\mathrm{CO}_{2}$ emissions associated to trade openness and the importance of trade openness associated to the share of non-renewable. In turn, about the effect of the weight of the share of non-renewable energy resources and renewable energy resources, provided their relationship with the variable economic growth (GDP), it is to be expected that higher levels of economic growth will drive to a higher tradeoff between the shares of non-renewable with that of renewable. As such, in the decomposition model we will have the relationship (cross product) between the share intensity of non-renewable and the productivity of renewable resources. Considering also that the renewable productivity and consequent technological change in energy production involve high investment amounts and these are intimal conditioned by the credit capacity of financial institutions ( $\mathrm{Fd}$ variable). So, we consider that changes in renewable shares are associated to higher or lower financing levels, justifying the inclusion of the relationship between renewables productivity with the effect called EF in our specification.

Changes in $\mathrm{CO}_{2}$ emissions may be assessed by using additive or multiplicative decompositions. In the present setting we decide to use the additive decomposition. The overall ratio of change in $\mathrm{CO}_{2}$ emissions between period's $\mathrm{t}$ and $\mathrm{t}-1$ may be decomposed as in equation (2).

$\Delta C O_{2}=C_{2} O_{2}-C_{2} O_{t-1}=\Delta C I+\Delta T F+\Delta F I+\Delta R P+\Delta \mathrm{EF}+\Delta F D$

where $\Delta \mathrm{CO}_{2}$ represents changes in aggregate $\mathrm{CO}_{2}$ emissions in each economy from one period to another, being in the right hand side the variables representative of the various contributing determinants as previously defined, but now being referred as to changes. Table 1 describes the formula for each effect in the additive decomposition (providing the formulas for each effect in the LMDI formula using the additive decomposition identity. 
Table 1 - Formulae for each effect in the additive decomposition.

\begin{tabular}{|l|l|}
\hline$\Delta C I_{\text {effect }}=\left(\frac{C O 2^{t}-C O 2^{t-1}}{\ln C O 2^{t}-\ln C O 2^{t-1}}\right) \times \ln \left(\frac{C I^{t}}{C I^{t-1}}\right)$ & $\Delta R P_{\text {effect }}=\left(\frac{C O 2^{t}-C O 2^{t-1}}{\ln C O 2^{t}-\ln C O 2^{t-1}}\right) \times \times \ln \left(\frac{R P^{t}}{R P^{t-1}}\right)$ \\
\hline$\Delta T F_{\text {effect }}=\left(\frac{C O 2^{t}-C O 2^{t-1}}{\ln C O 2^{t}-\ln C O 2^{t-1}}\right) \times \ln \left(\frac{T F^{t}}{T F^{t-1}}\right)$ & $\Delta E F_{\text {effect }}=\left(\frac{C O 2^{t}-C O 2^{t-1}}{\ln C O 2^{t}-\ln C O 2^{t-1}}\right) \times \ln \left(\frac{E F^{t}}{E F^{t-1}}\right)$ \\
\hline$\Delta F I_{\text {effect }}=\left(\frac{C O 2^{t}-C O 2^{t-1}}{\ln C O 2^{t}-\ln C O 2^{t-1}}\right) \times \ln \left(\frac{F I^{t}}{F I^{t-1}}\right)$ & $\Delta F d_{\text {effect }}=\left(\frac{C O 2^{t}-C O 2^{t-1}}{\ln C O 2^{t}-\ln C O 2^{t-1}}\right) \times \ln \left(\frac{F d^{t}}{F d^{t-1}}\right)$ \\
\hline
\end{tabular}

Note: CI denotes carbon trade intensity, TF the trade of fossil fuels effect, FI fossil fuels intensity, RP renewable sources productivity, EF electricity financial power effect, Fd the financial development effect; $\Delta$ stands for changes between $\mathrm{t}$ and $\mathrm{t}-1$.

Equation (2) captures the carbon trade intensity effect (CI), since the variable $\Delta \mathrm{CI}$ represents changes in $\mathrm{CO}_{2}$ emissions from trade openness activity between period $\mathrm{t}$ and $\mathrm{t}-1$, respectively. The CI factor captures the trade openness transfers of advanced technology from the developed world towards developing and emerging economies which might be helpful to lower energy pollutants [60].

In equation (2) we also account for the trade fossil fuel penetration effect, TF. Variable $\Delta \mathrm{TF}$ shows the share of trade openness with respect to total electricity power from non-renewable sources between t and t-1, respectively. According to [60], trade openness may affect energy consumption through the income effect, technique effect and also through the composite effect. These will clearly impact $\mathrm{CO}_{2}$ emissions.

From Table 1 and equation (2) we see the inclusion of the fossil fuels intensity effect, FI. Variable $\Delta \mathrm{FI}$ in the setting denotes changes in electricity power from nonrenewable sources (coal, oil and natural gas) used in economic activities between period $\mathrm{t}$ and $\mathrm{t}-1$, respectively.

On the other side we have included the productivity of the electricity power from renewable sources, RP, being that variable $\triangle \mathrm{RP}$ denotes changes in income or economic value per electricity power obtained through wind, solar, geothermal, biomass and waste used between periods $\mathrm{t}$ and $\mathrm{t}-1$, respectively. The RP factor captures the income effect on $\mathrm{CO}_{2}$ emission changes from electricity power generated from renewable sources.

In estimations we have also considered the multiplicative effect of these last two factors FI $\mathrm{x} R \mathrm{R}$, which respectively represent the share of renewable and non-renewable sources. This cross effect indicates an aggregate proxy effect of the energy technology level of a country's economy. It may be seen as a signal indicating the technology efficiency of the energy 
system, countries technological choices, energy prices, energy conservation techniques and of investments performed for energy savings as also argued by [61].

In Table 1 and equation (2) we also account for the financial electricity renewable effect $(\mathrm{EF})$, where the variable $\Delta \mathrm{EF}$ measures the impact of the electricity power generation from renewable sources in terms of financial development, incorporating the relative effect of internal financing in the private sector between period $\mathrm{t}$ and $\mathrm{t}-1$, respectively. Moreover, renewable sources are expected to affect demand for internal finance and thus financial depth. In particular, when a wealthy country starts using new technology efficiency of the energy system by using a poor one, it will naturally increase production by renewable sources and the financially dependent energy source will shrink. This will lead to deterioration in the country's financial system size, as well as its energy quality or electricity generation. As a consequence, this will increase the trade-off between electricity power generation by renewable and non-renewable sources.

Finally, we also account for financial development; $\mathrm{Fd}$. Variable $\Delta \mathrm{Fd}$ denotes changes of the internal credits in the private sector between period t and t-1, respectively. As [62] point out, increases in financial development can also help countries, through technology spillovers, adopting and using new environmentally friendly technologies. This will even enhance their internal economic growth and development.

\section{Results and Discussion}

Figure 1 results, from the decomposition for the panel of 23 countries in our sample, show that there were high negative and significant variations in $\mathrm{CO}_{2}$ emission changes between the years 1989 and 2004 when compared to 1988 and 2003, respectively. These counterbalance with high positive and significant variations in years 1990 and 1998 when compared to 1989 and 1987, respectively. In the last years of our analysis there exists a reduced change in emissions in the years 2007 to 2008, 2009 to 2010 and 2011 to 2010, by opposition to the positive variation noticed between 2008 and 2009.

The change from positive carbon emission variations to negative ones represent a movement from increased changes to that of diminishing variations in emissions. We need to highlight fundamentally the joint important contributions of the productivity of renewable resources effect in electricity production (RP effect) and that of domestic financing to incentivize renewables investments (EF effect). It should be also stressed that in the 90s, specifically in 
1992 as compared to 1991, the negative and significant impact of EF (547\%) and that of Fd (104\%) more than compensated the positive and significant impact of the RP effect (-648\%) in the total $\mathrm{CO}_{2}$ emissions variation ${ }^{4}$. In the years 1994-1995, we register the negative impact of the FI effect (14.9\%) and that of EF effect (46.8\%) which surpass the positive impact of the RP effect (49\%) in total emissions variations. In turn, in the year 1999 with respect to 1998 we verify that the negative effect of the EF impact (94.8\%) and of FI (21.9\%) more than compensated the negative impact of the RP effect $(85.7 \%)$ in total emission $\mathrm{CO}_{2}$ changes. In $2001^{5}$, the negative and significant impacts of RP (379.8\%) and of FI (142.9\%) more than compensate the positive and significant EF effect (-334.6\%) and that of TF ($146.7 \%$ ) in total $\mathrm{CO}_{2}$ emission changes.

\footnotetext{
${ }^{4}$ Table A.1 at the appendix presents all these percentage values of effects variation contribution to $\mathrm{CO}_{2}$ emissions. We have a negative impact when the effect change is positive because this means a positive contribution to emissions increases, and a positive impact when the effect change is negative, meaning that it negatively contributed to emission decreases being this a good impact.

${ }^{5}$ When we talk about a given year from here onwards we mean the value of the change verified in that year with respect to the previous one. So the value in 2001 , for example, is with respect to the change as compared to 2000 .
} 
Figure 1 - Top renewable energy 23 countries $-\mathrm{CO}_{2}$ emissions LMDI decompositions and $\mathrm{CO}_{2}$ emissions changes

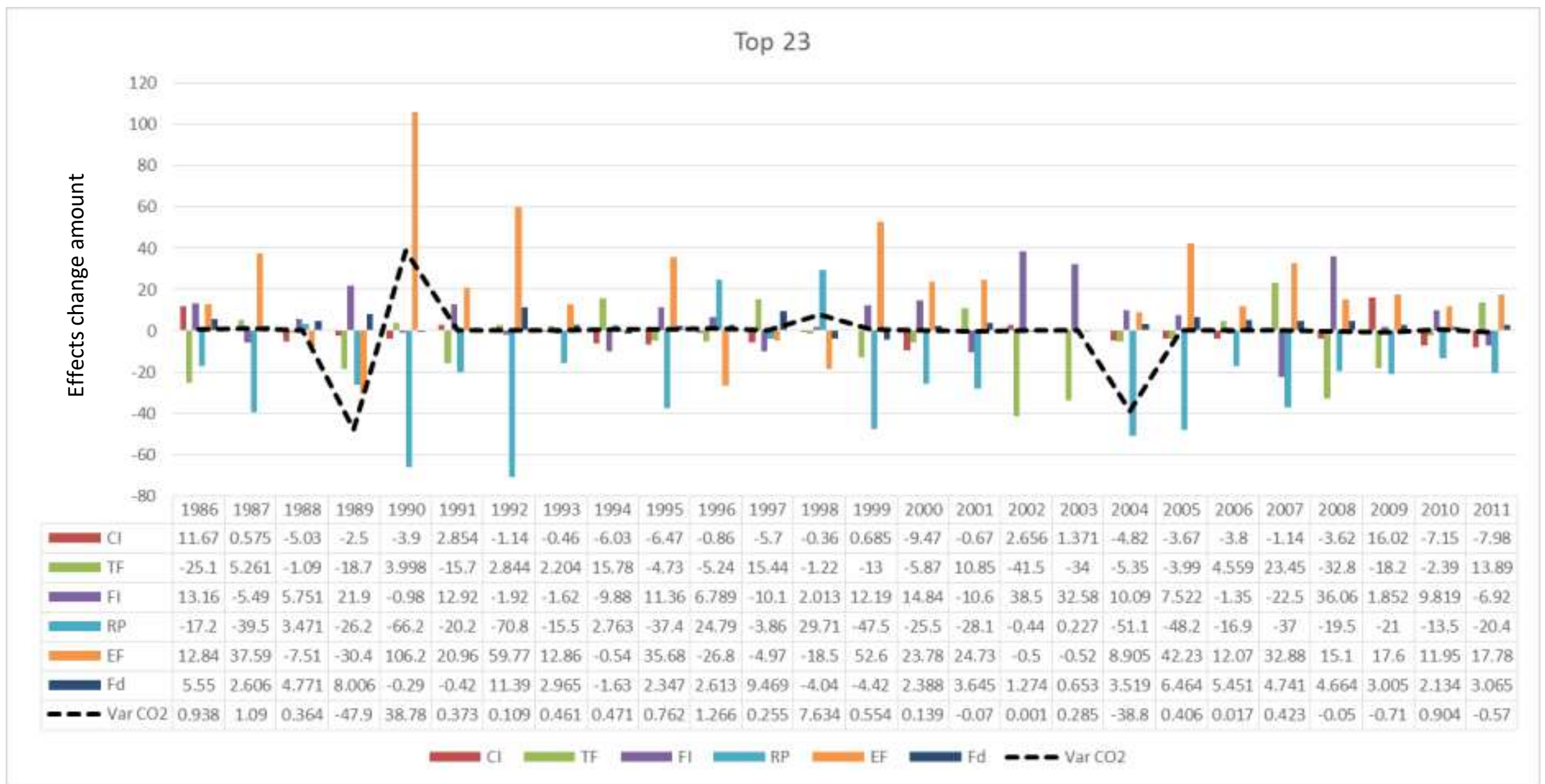

Note: CI denotes carbon trade intensity, TF the trade of fossil fuels effect, FI fossil fuels intensity, RP renewable sources productivity, EF electricity financial power effect, Fd the financial development effect; $\operatorname{Var} \mathrm{CO}_{2}$ stands for $\mathrm{CO}_{2}$ emission changes between $\mathrm{t}$ and $\mathrm{t}-1$ due to the six considered effects. 
We should also notice that in 2008, the positive impact of FI (-662.7\%) and of the EF ($277 \%$ ) effect are opposed to the negative and significant effects of RP (357.8\%) and of TF $(601 \%)$ and these have compensated them provided the negative changes in emissions verified. In 2010 we verify a positive change but very insignificant in emission changes which may be explained by the moderate and negative effect FI (10.9\%) and of EF (13.2\%), which surpass the positive impacts also moderated of the CI effect (-7.9\%) and of RP (14.9\%) effects. In 2011 we turn to observe an inversion, by registering a negative and moderate change of $\mathrm{CO}_{2}$ emissions, whose inversion is explained by the also smooth negative effects of CI (13.9\%) and FI (12\%) and more pronounced in RP (35.7\%), which jointly surpassed the positive effects of TF (-24.3\%) and of the EF effect $(-31 \%)$.

Summing up, in this group of 23 countries of Top renewable energy it was verified the predominance of the positive and significant in magnitude EF effect with higher magnitudes in its annual change in the decade of the 90s and with a verified decrease in that positive impact in the change occurred in the last analyzed years. In turn, the negative and highly significant impact of the RP effect, as it accompanied somehow the annual magnitude changes, is revealed by the temporal behavior of the EF effect. It is even visible from figure 1 the jumps in $\mathrm{CO}_{2}$ emissions verified in the years 1989-1990, 1998-1999 and 2004-2005; the first and the last being negative, and in 1998-1999 a primer positive moderate jump. These may be justified by the policies adopted, for example, as the Kyoto protocol in 2005.

Given that the total sample incorporates countries from Europe and countries from other continents including America and Africa, with different levels with respect to renewable sources used in electricity production, this has lead us to consider different sub aggregated groups of countries to perform a separate decomposition analysis of $\mathrm{CO}_{2}$ emissions. As such, next we present the highest 23 group separation analysis into two distinct sub groups: the European countries in the sample and the rest of world countries. In this sense we are able to verify with respect to the already found evidence that negative emission changes occurred in 1989 and 2004 are implicitly referred to this group of European countries, as in accordance with the results presented in figure 2 .

The subgroup of European countries includes Austria, Belgium, Denmark, France, Italy, Netherlands, Norway, Portugal, Spain, Sweden, Turkey and the United Kingdom. In this group we may verify that in aggregate terms there is a clear tendency to changes from positive to negative, with predominance of positive ones mainly in the 1990 period. 
Figure 2 - Top renewable energy European group of countries - $\mathrm{CO}_{2}$ emissions LMDI decompositions and $\mathrm{CO}_{2}$ emissions changes

Top EU countries

80

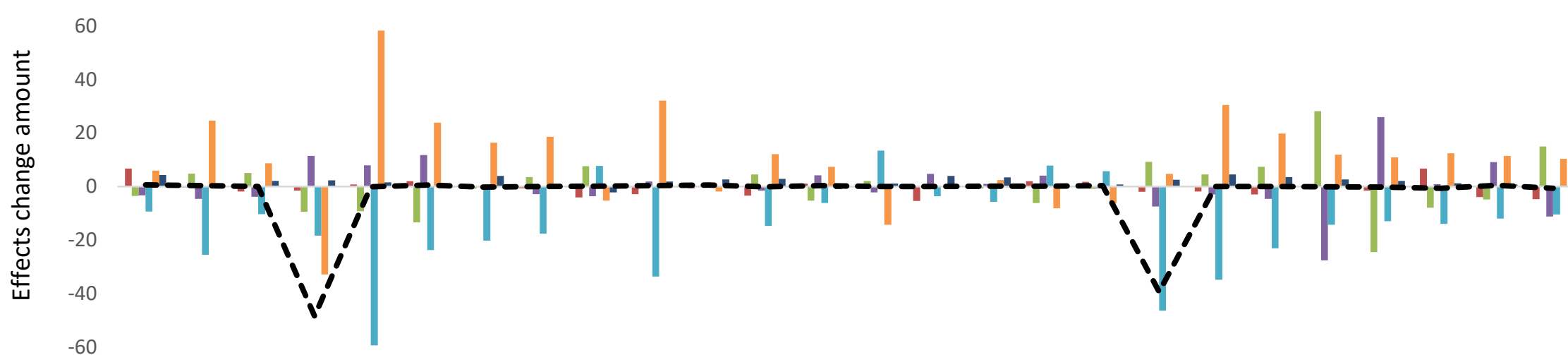

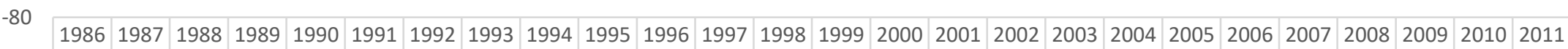
\begin{tabular}{|l|l|l|l|l|l|l|l|l|l|l|l|l|l|l|l|l|l|l|l|l|l|l|l|l|l}
6.67 & -0.32 & -1.82 & -1.55 & 0.761 & 2 & 0.228 & -0.67 & -4.07 & -2.82 & -0.63 & -3.4 & 1.113 & -0.05 & -5.41 & -0.11 & 2.011 & 1.814 & -1.94 & -1.81 & -3 & -0.82 & -1.57 & 6.714 & -4 & -4.67 \\
\hline
\end{tabular}

$\mathrm{Cl}$ TF \begin{tabular}{ll|l|l|l|l|l|l|l|l|l|l|l|l|l|l|l|l|l|l|l|l|l|l|l|l|l|l|l|l|l}
-3.56 & 4.889 & 5.114 & -9.4 & -9.25 & -13.4 & -0.75 & 3.495 & 7.634 & 1.007 & 0.355 & 4.49 & -5.25 & 2.071 & 0.327 & -0.79 & -6.11 & -0.86 & 9.194 & 4.506 & 7.377 & 28.11 & -24.5 & -7.96 & -4.85 & 15
\end{tabular}

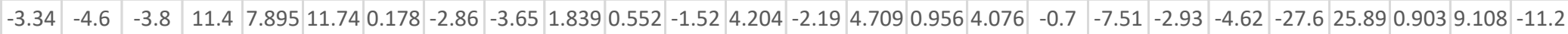
$\begin{array}{llllllllllllllllllllllllllllll}-9.34 & -25.5 & -10.3 & -18.3 & -59.3 & -23.8 & -20.2 & -17.6 & 7.662 & -33.7 & -0.44 & -14.8 & -6.15 & 13.46 & -3.65 & -5.68 & 7.864 & 5.764 & -46.3 & -34.8 & -23 & -14.2 & -13 & -14 & -12 & -10.4\end{array}$

RP

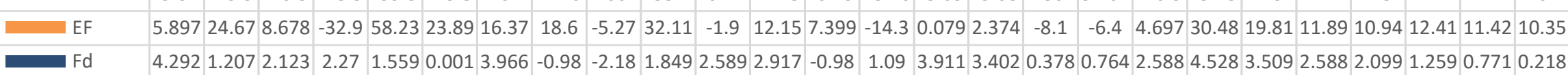

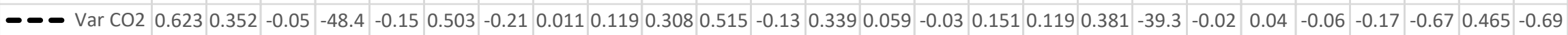
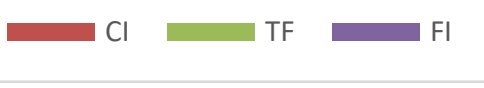

Note: CI denotes carbon trade intensity, TF the trade of fossil fuels effect, FI fossil fuels intensity, RP renewable sources productivity, EF electricity financial power effect, Fd the financial development effect; $\mathrm{Var} \mathrm{CO}_{2}$ stands for $\mathrm{CO}_{2}$ emission changes between $\mathrm{t}$ and $\mathrm{t}-1$ due to the six considered effects. 
The predominance of positive changes with respect to negative ones in the $90 \mathrm{~s}$ is in terms of signs but not with respect to magnitude in absolute terms. This means that the negative values in 1992 are so high that they would eliminate all the positive changes verified in emissions (lower and not so significant in absolute terms). By opposition, in the 2000 decade, where there exists a predominance of negative changes in emissions as compared to the positive ones, evidence is reinforced by the significant and negative value occurred in 2005 as compared to 2004. Values confirming the contributions of each considered effect over total $\mathrm{CO}_{2}$ changes (computed as $\Delta$ effect $/ \Delta \mathrm{CO}_{2}$ for each year) are presented in Table A.2 at the appendix for Europe and in Table A.3 at the appendix for the Rest of the World group.

We need to consider that along this period it is verified a predominance of negative changes in the European countries set which occurred in the year 1989 with $\mathrm{CO}_{2}$ variations hitting a negative change amount and significant of 48.44 tons. This was caused mainly by the positive impact of effects FI and Fd. Results also point for a negative value in 1990 but not that significant of -0.15 due to the positive impacts of FI and EF with high magnitude of $52.57 \%$ and $-387.7 \%$, respectively, which has not been compensated by the negative changes verified in TF and RP, of $61.6 \%$ and 395.15\%, respectively. In the year 1992 we still have a negative change of $\mathrm{CO}_{2}$ emissions with these varying negatively but with lower significance between 1991 and 1992 of -0.208 ton resulting from the positive impact of the EF effect and from Fd, where the negative impact of RP was not able to compensate them. In turn, in the year 2005 we verify a negative change of -0.02 ton in face of the negative change verified in 2004 of -39.315 ton. In 2005 the change was mainly due to TF, EF and Fd effects which more than compensated the negative RP effect.

In the period after the Kyoto agreement there is in this subgroup of countries a predominance of negative variations in emissions although with no greater magnitudes, considering the results obtained. More specifically, in the year 2007 there is a variation surrounding the 0.064 ton in emissions caused by the positive changes of the effects TF and EF which more than compensated the negative ones of FI and RP. In 2008 we verify a continuous moderate reduction in $\mathrm{CO}_{2}$ emissions as well as in 2009 and 2011, where in 2011 they hit -0.694 ton variation of $\mathrm{CO}_{2}$ emissions being mainly caused by the positive impacts of $\mathrm{TF}$ and $\mathrm{EF}$, not compensated by the FI and RP negative effects of $16 \%$ and $15 \%$ respectively.

Finally we should notice the two negative, followed by positive jumps in $\mathrm{CO} 2$ emissions, changes verified in figure 2. These occur in the years 1989-1990 and in the years 2004-2005, 
but no positive and significant jump is observed in this sub group, as compared to the previous results in the set of 23 Top ranked countries in renewables.

In general terms and for this subgroup of European countries our results point for the importance of the effects FI, RP and EF as the main drivers to explain $\mathrm{CO}_{2}$ emissions changes and so we will analyze these same effects along the considered period but disaggregating our sample, meaning, performing an evaluation of each impact effect at each country level.

Results are presented in Tables 2, 3 and 4.

Table 2 - FI factor decomposition and impact by years for each country in the European subgroup

\begin{tabular}{|c|c|c|c|c|c|c|c|c|c|c|c|c|}
\hline$\Delta \mathbf{F I}$ & Austria & Belgium & Denmark & France & Italy & Netherlands & Norway & Portugal & Spain & Sweden & Turkey & Ukingdom \\
\hline 1986-1985 & -0.0332 & -1.1608 & 0.5686 & -1.3276 & 0.1176 & 0.2773 & -5.3598 & 2.8615 & -0.1739 & 0.3187 & 0.4932 & 0.0779 \\
\hline $1987-1986$ & 0.4234 & 0.6895 & -0.2437 & -0.4593 & 0.5278 & 0.1247 & -3.3730 & -0.5091 & -0.3627 & -0.6210 & -0.8657 & 0.0664 \\
\hline 1998-1987 & -0.7315 & 0.3191 & -0.3945 & -0.2759 & -0.4687 & 0.0502 & 2.6341 & -1.7457 & -1.2122 & -0.6564 & -1.2341 & -0.0814 \\
\hline 1989-1988 & 0.7995 & 1.0830 & -1.1542 & 1.5875 & 0.7736 & 0.1753 & -0.5459 & 5.6282 & 1.6899 & -1.3722 & 2.7767 & -0.0456 \\
\hline 1990-1989 & 1.2190 & 0.2354 & 0.7232 & -0.4871 & 0.1701 & -0.1417 & 12.4248 & -0.4442 & -0.0506 & -6.4982 & 0.6748 & 0.0695 \\
\hline 1991-1990 & 0.5667 & 0.1375 & 1.8281 & 1.2420 & -0.1303 & 0.1473 & 1.6588 & 0.4073 & 0.0118 & 5.4025 & 0.4615 & 0.0027 \\
\hline 1992-1991 & -1.4696 & -0.1265 & -1.0128 & -0.9285 & 0.0999 & 0.1229 & -0.0787 & 1.1210 & 0.5830 & 1.6208 & 0.3954 & -0.1491 \\
\hline 1993-1992 & 0.7148 & 0.0644 & 0.5032 & -2.0442 & -0.0710 & -0.0440 & -0.6239 & -0.6356 & -0.4003 & 1.4906 & -0.1734 & -0.2097 \\
\hline 1994-1993 & 0.9056 & 0.4728 & 0.8442 & -0.1759 & 0.1160 & 0.1367 & -7.8855 & -0.5440 & 0.1170 & 1.4021 & 0.9552 & 0.0070 \\
\hline 1995-1994 & 0.4086 & 0.2214 & -0.5339 & 0.7215 & 0.2930 & 0.0333 & -0.7305 & 1.0764 & 0.4825 & -0.4270 & 0.2273 & 0.0660 \\
\hline 1996-1995 & 0.5257 & -0.0586 & 1.9025 & 0.6390 & -0.0635 & 0.1690 & -4.7760 & -1.4712 & -0.5794 & 3.7097 & 0.2974 & 0.2574 \\
\hline 1997-1996 & 0.0491 & -0.2616 & -1.0824 & -0.6053 & 0.1188 & 0.0760 & 2.4113 & 0.3758 & 1.0529 & -4.2073 & 0.6785 & -0.1211 \\
\hline 1998-1997 & -0.3198 & 0.8917 & -0.5554 & 7478 & 0.1128 & 0.1137 & 0.8851 & 1.2488 & -0.0019 & -0.4205 & 0.3605 & 0.1415 \\
\hline 1999-1998 & -0.1218 & -0.2994 & -0.4156 & -0.4885 & -0.0005 & -0.2823 & -3.9814 & 1.7275 & 0.8328 & -0.0554 & 0.8067 & 0.0843 \\
\hline 2000-1999 & 2093 & 226 & 053 & 058 & 724 & 519 & 874 & 755 & 222 & 082 & 5617 & 2284 \\
\hline $2001-2000$ & 0.8416 & -0.4581 & 0.2350 & -0.5129 & -0.0434 & 0.1803 & -2.3404 & -0.0266 & -0.1593 & 2.9941 & 0.2467 & -0.0008 \\
\hline $2002-2001$ & -1.0204 & 0.2196 & 0.0943 & 0.6539 & 0.1947 & 0.0834 & -0.4596 & 0.8710 & 0.7135 & 1.8817 & -0.1717 & 0.0155 \\
\hline 2003-2002 & 1.1775 & 0.4419 & 0.8201 & 0.4294 & 0.1544 & 0.0313 & -4.8101 & -1.1705 & -0.1386 & 1.8925 & 0.3676 & 0.1018 \\
\hline 2004-2003 & -0.1937 & 0.0400 & -1.1132 & -0.1023 & 0.0220 & 0.2035 & -2.2394 & 0.6414 & 0.5177 & -5.2035 & -0.0893 & 0.0031 \\
\hline 2005-2004 & 205 & 552 & -0.9180 & 0.5741 & 882 & 5 & -1.0546 & 0.7898 & 281 & -3.6396 & 0.5912 & -0.0276 \\
\hline 2006-2005 & -0.6956 & -0.2453 & 1.7194 & -0.5571 & 0.1116 & -0.1151 & -5.4035 & -0.7551 & -0.0669 & 1.1169 & 0.2570 & 0.0171 \\
\hline 2007-2006 & -0.6080 & 0.1220 & -1.2216 & 0.0776 & 0.0379 & 0.2809 & -24.4643 & -0.3794 & 0.0773 & -2.2339 & 0.6131 & 0.1097 \\
\hline $2008-2007$ & 0.1630 & -0.3656 & -0.5143 & -0.1978 & -0.0644 & 0.0152 & 26.1767 & 0.0251 & 0.0201 & 0.4151 & 0.2131 & 0.0065 \\
\hline 2009-2008 & -0.2577 & 0.5595 & 0.0053 & -0.4534 & -0.5271 & 0.2228 & 1.6386 & 0.0810 & -0.5145 & 0.6463 & -0.1419 & -0.3561 \\
\hline 2010-2009 & 1.1322 & 0.2722 & 0.0235 & 0.5933 & 0.0254 & 0.1810 & 1.6441 & -1.1639 & -0.6840 & 7.0349 & -0.0936 & 0.1425 \\
\hline 2011-2010 & -0.4494 & -1.0440 & -1.3667 & -0.94015 & -0.07829 & -0.2955 & -1.97056 & 0.5275 & 0.2173 & -5.6758 & 0.3156 & -0.4084 \\
\hline
\end{tabular}

Source: Own elaboration.

In accordance to Table 2, the impact of the effect of fossil fuel resources intensity in electricity generation (FI effect) is important at the significance level of the negative amplitudes (or of positive variations impacts) to mitigate emission, especially in Norway and 
Sweden. More specifically, in the year 1990 with respect to 1989 and in the period 2000 in face of 1999 we observe that in Norway we have a greater positive change of this effect, while Sweden presents the highest negative change, as compared to changes occurred in this same effect for the rest of the countries inside this subgroup. In the periods 1994-1993, 19961995 and 2003-2002 there exists an inversion into the behavior of this effect with Norway revealing the highest negative change and Sweden presenting the highest positive variation with respect to the rest of the countries. However, in 2004-2003, 2007-2006 and 2011-2010, in both countries, Norway and Sweden we verify the highest negative changes of this effect which evaluates the energy intensity, where Sweden presents the highest negative impact of the FI effect in the periods 2004-2003 and 2011-2010. In turn, Norway reveals the highest negative variation in 2007-2006. We would like to notice that both countries Norway and Sweden reveal the highest positive change in the energy intensity in the period 2008-2007 when compared to the other countries in this sub-group.

Turning our attention to the RP effect, whose results are presented in table 3 , the impact of the productivity of renewables effect in electricity generation (RP) is one of the most important at the significance level considering the negative amplitudes (or of positive changes) impact to explain emission variations occurred mainly in Austria, Denmark, Belgium and Turkey during the 90s decade. More specifically, in the years 1987-1986 there exists a contribution in the sense of negative variation more significant in Turkey followed by Austria and a more positive change in Denmark followed by Belgium. In turn, in 19891988 there seems to exist an inversion in this importance degree since Denmark presents a higher negative variation followed by Austria, while Turkey presents a higher positive change followed by Belgium.

In the year 1995-1994, the highest negative variation is verified in Austria followed by the countries Denmark and Turkey, with Belgium presenting the highest positive variation in this effect. In the period 1999-1998, Belgium presents the highest positive variation of this effect followed by Turkey and Austria while Denmark presents a slightly and negative change in this effect of productivity of renewable resources. Along the entire 2000 decade, only Belgium and Turkey are highlighted into the behavior of this RP effect, such that renewables productivity in this decade changed with some intensity in these three economies inside the sub group of European countries. As such, in 2002-2001, Turkey presents the highest contribution in the negative change of this effect by opposition to the highest changes verified in Belgium and Austria. In the 2003-2002 periods we have Austria presenting a 
higher negative variation in the renewables productivity while Belgium and Turkey present the highest positive changes. By turn, in 2004-2003 and 2006-2005 in all these three economies we verify negative changes in the RP productivity with Belgium results point for the highest variation of the effect. This joint tendency in these three economies of a negative RP change is repeated in 2010-2009 and 2011-2010 with Turkey presenting the highest negative impact in this change in 2010-2009, while in 2011-2010 it is Belgium that presents the highest negative variation in this effect.

Table 3 - RP factor decomposition and impact by years for each country in the European subgroup

\begin{tabular}{|c|c|c|c|c|c|c|c|c|c|c|c|c|}
\hline$\Delta \mathrm{RP}$ & Austria & Belgium & Denmark & France & Italy & Netherlands & Norway & Portugal & Spain & Sweden & Turkey & Ukingdom \\
\hline 1986-1985 & -0.1983 & 0.2054 & 1.0613 & 0.1726 & 0.0282 & -1.5700 & 0.9867 & -0.4829 & -0.0657 & 0.4931 & 0.8124 & 2.8496 \\
\hline $1987-1986$ & 0.1315 & 3995 & -0.4374 & 0.3086 & 0.0761 & 0.2108 & 0.5114 & -0.3530 & 0.2478 & -0.5735 & 0.3507 & 0.3350 \\
\hline $1998-1987$ & 0.2064 & 0.5961 & -0.1567 & 0.1757 & 0.2516 & 0.7353 & 0.1084 & -0.1861 & 0.4435 & 0.5269 & -1.0763 & 0.4977 \\
\hline $1989-1988$ & 0.1897 & 0.8160 & 0.2717 & 0.2123 & 0.0464 & 0.0644 & 0.0858 & -0.2156 & 0.2518 & 0.2820 & -0.2680 & 0.5332 \\
\hline 1990-1989 & 0.1859 & -0.0108 & -0.0429 & 0.2609 & 0.2155 & 0.0694 & -0.0360 & -0.0823 & -0.0293 & 0.8677 & 0.0788 & 0.0822 \\
\hline 1991-1990 & 0.0586 & 2116 & -0.8447 & 0.0544 & 0.2269 & 0.1062 & -0.3917 & 0.4755 & 0.1023 & -0.0851 & 0.1995 & -0.1125 \\
\hline 1992-1991 & 0.0367 & 3.3680 & -0.2883 & 0.0287 & 0.2602 & 0.0547 & -0.0424 & 0.3068 & -0.0926 & 0.0351 & 0.3244 & -0.0248 \\
\hline 1993-1992 & 0.0438 & -0.0597 & -0.6874 & -0.1877 & 0.0089 & 0.1662 & -0.1077 & 0.2386 & -0.1111 & -0.3478 & 0.1184 & -0.0593 \\
\hline 1994-1993 & -0.0460 & -0.0681 & -0.6071 & -0.2089 & -0.2104 & 0.1286 & 0.0338 & 0.1038 & -0.1932 & -0.2622 & -0.8893 & 0.0349 \\
\hline 1995-1994 & 0.1043 & -0.0527 & 0.0343 & -0.0223 & -0.1323 & 0.2887 & 0.1304 & 0.4442 & -0.0247 & -0.2259 & 1.0402 & 0.2651 \\
\hline 1996-1995 & 0.1394 & 0.1357 & 0.1303 & -0.1659 & -0.1336 & 0.2937 & 0.1937 & 0.4593 & 0.0630 & -0.0503 & 1.3784 & 0.1451 \\
\hline 1997-1996 & 0.2297 & 0.0608 & 0.1094 & -0.0384 & 0.0826 & 0.2415 & 0.4021 & 0.4639 & 0.3341 & 0.0511 & 0.8971 & 0.0831 \\
\hline 1998-1997 & -0.2791 & -0.3890 & 0.4530 & -0.0121 & 0.2349 & 0.1389 & 0.4545 & 0.5888 & 0.4083 & 0.0371 & -2.6476 & 0.0302 \\
\hline 1999-1998 & 0.0483 & -0.0158 & -0.0156 & 0.0067 & 0.2924 & 0.1579 & -0.0949 & 0.3779 & 0.3708 & 0.0627 & -0.2493 & 0.1488 \\
\hline 2000-1999 & 0.0425 & 231 & 5.8018 & 0.0488 & 0.1819 & 0.1330 & -0.1590 & 0.2410 & 0.3795 & -3.6198 & 0.4885 & 0.3501 \\
\hline 2001-2000 & -0.1600 & -0.0589 & 0.1891 & -0.1379 & -0.0114 & 0.1809 & 0.2909 & 0.4675 & -0.0597 & 3.5234 & -1.0341 & 0.2124 \\
\hline 2002-2001 & -0.0426 & -0.1418 & 0.0742 & -0.0458 & 0.1336 & -0.0339 & 0.2771 & 0.1355 & 0.2053 & 0.0263 & -0.3501 & 1402 \\
\hline 2003-2002 & -0.0203 & -0.1024 & -0.0359 & -0.0248 & 0.2453 & -0.0181 & 0.1546 & 0.0439 & 0.3132 & 0.0122 & 0.0491 & 0.1467 \\
\hline 2004-2003 & 0.0154 & -0.0326 & 0.1589 & 0.0828 & 0.1816 & 0.1715 & 0.0196 & 0.0278 & 3712 & 0.0973 & 1.2616 & 0.2329 \\
\hline 2005-2004 & 0.3065 & 454 & 0.2900 & 0.2180 & 0.2185 & 0.1456 & 0.2048 & 0.1147 & 0.6679 & 0.3279 & 1.6950 & 0.1940 \\
\hline 2006-2005 & 0.0307 & 0.1572 & 0.2708 & 0.2438 & 0.3266 & -0.0706 & 0.2679 & 0.2605 & 0.5882 & 0.1585 & 0.9819 & 0.2939 \\
\hline 2007-2006 & -0.0369 & 0.2027 & 0.3061 & 0.2518 & 0.3627 & 0.0148 & -0.5453 & 0.2498 & 0.2901 & 0.3189 & 0.7841 & 0.3893 \\
\hline 2008-2007 & 0.1347 & -0.3997 & 0.1238 & 0.1828 & 0.0960 & -0.0703 & 0.0462 & 0.2313 & 0.0768 & 0.2168 & 0.9977 & 0.4625 \\
\hline 2009-2008 & 0.0534 & -0.3207 & 0.1446 & 0.0987 & 0.1596 & 0.1729 & 0.0591 & 0.1642 & 0.0243 & 0.1856 & 0.5387 & -0.0218 \\
\hline 2010-2009 & 0.0416 & -0.1217 & -0.1209 & 0.0494 & 0.2843 & -0.1135 & 0.0512 & -0.0875 & -0.0370 & -0.0063 & 1.0223 & -0.1910 \\
\hline $2011-2010$ & -0.0841 & -0.1169 & -0.0927 & 0.0613 & 0.0623 & 0.0400 & 0.0314 & 0.0069 & -0.1102 & 0.0770 & 0.6561 & -0.3127 \\
\hline
\end{tabular}

Source: Own elaboration.

With respect to the importance of the EF effect, which translates the capturing effect of financial domestic credits to incentivize investments into renewable resources in electricity production, and in accordance to the results presented in Table 4, the behavior of this effect 
seems not to be dissociated of the impact of the productivity of renewables discussed previously to explain changes in emissions occurred. With respect to the importance of these two effects, we highlight Austria, Denmark, Belgium and Turkey along the 90s decade. In detail, in 1989-1988 we observe that in Denmark we have a higher negative change of this effect followed by Turkey and Belgium, while it is Austria which presents a positive change occurred in this effect with respect to the rest of the countries which compose this sub group sample. In the following period of 1991-1990 and in 1995-1994 there exists a higher positive variation of this effect in Austria and in Turkey followed by Denmark, while Belgium is the country which presents the highest negative EF effect variation.

Table 4 - EF factor decomposition and impact by years for each country in the European subgroup

\begin{tabular}{|c|c|c|c|c|c|c|c|c|c|c|c|c|}
\hline$\Delta \mathrm{EF}$ & Austria & Belgium & Denmark & France & Italy & Netherlands & Norway & Portugal & Spain & Sweden & Turkey & Ukingdom \\
\hline 1986-1985 & 0,3141 & $-6,0431$ & $-8,9042$ & 0,3112 & 0,6115 & 5,6524 & $-4,9773$ & $-0,4587$ & $-0,3298$ & $-0,1794$ & 22,5355 & $-2,6355$ \\
\hline $1987-1986$ & 12,4105 & $-2,3607$ & $-4,5906$ & $-0,1489$ & $-0,9230$ & 1,5055 & $-4,9835$ & 0,8365 & 0,2454 & 0,5549 & 22,6550 & $-0,5283$ \\
\hline 1998-1987 & 7,0076 & $-3,0218$ & $-13,7863$ & $-0,1240$ & $-0,0704$ & 2,0264 & 5,0609 & 1,3325 & 1,3295 & $-0,3815$ & 9,9541 & $-0,6491$ \\
\hline 1989-1988 & 16,8939 & $-1,3913$ & $-13,7171$ & 1,3320 & $-2,1240$ & 1,4178 & 1,1647 & $-4,2829$ & $-2,4852$ & 0,0037 & $-11,2519$ & $-18,4123$ \\
\hline 1990-1989 & 0,3146 & $-4,6132$ & 35,6625 & 1,1663 & $-0,5641$ & $-3,2108$ & 18,5506 & 2,3524 & 0,4038 & $-1,2788$ & 7,8913 & 1,5576 \\
\hline 1991-1990 & 12,4559 & $-1,0853$ & 3,7839 & 0,2232 & 1,0503 & 1,0779 & 0,2823 & 0,1307 & $-0,0037$ & $-0,1050$ & 4,5230 & 1,5566 \\
\hline 1992-1991 & 7,0324 & $-1,8399$ & 8,6466 & 0,1438 & 0,0209 & 1,3745 & 0,5133 & $-3,2771$ & 0,5204 & 0,2454 & 0,0341 & 2,9593 \\
\hline 1993-1992 & 0,7442 & 1,2210 & 3,1817 & 0,0595 & 0,3076 & 2,0214 & 0,6414 & 2,9154 & 0,7207 & 0,6031 & 3,1612 & 3,0182 \\
\hline 1994-1993 & $-11,0301$ & 0,0229 & 0,6071 & 0,5588 & 0,0745 & 1,1434 & 0,5156 & 1,3040 & 1,0627 & 0,3426 & $-1,2448$ & 1,3688 \\
\hline 1995-1994 & 24,7344 & $-3,6937$ & 1,8306 & 0,2657 & $-0,6947$ & 1,0753 & 0,2328 & $-1,5384$ & 1,8366 & 0,4690 & 7,4865 & 0,1014 \\
\hline 1996-1995 & $-5,8008$ & 0,2515 & $-1,0743$ & 0,2899 & 1,1995 & 2,4831 & 0,0257 & 1,8539 & 1,2213 & $-0,3563$ & $-2,4130$ & 0,4154 \\
\hline 1997-1996 & 3,1898 & 1,8440 & 5,7105 & 0,4443 & 0,2237 & $-1,2483$ & $-1,5377$ & $-0,4837$ & 0,8615 & 0,9881 & 1,1114 & 1,0443 \\
\hline 1998-1997 & 3,1338 & $-3,8097$ & 2,8761 & $-0,1280$ & 0,2300 & 2,5523 & 0,1372 & $-1,0566$ & 0,7250 & 0,1085 & 1,6165 & 1,0136 \\
\hline 1999-1998 & $-4,8252$ & $-6,6869$ & 1,3302 & 0,3112 & 0,6022 & 0,9753 & 4069 & $-2,6451$ & 6208 & $-0,1067$ & $-4,8222$ & 0,5247 \\
\hline 2000-1999 & $-1,0607$ & $-3,8607$ & $-3,5035$ & 0,1726 & 0,0697 & 1,0709 & $-0,0219$ & 2,4316 & 0,9667 & 4,8764 & $-0,7477$ & $-0,3142$ \\
\hline $2001-2000$ & 4,0035 & 813 & 0,0159 & 0,6176 & 39 & 0,5145 & 035 & 0,6162 & 4358 & $-3,7436$ & 0,7490 & 0,4665 \\
\hline $2002-2001$ & $-2,3259$ & $-9,2544$ & 0,8523 & 0,3171 & $-0,1336$ & 1,3567 & 0,4666 & $-1,7375$ & 0,2764 & 0,2755 & 1,4081 & 0,4001 \\
\hline 2003-2002 & 6,9915 & $-18,1658$ & 0,7076 & 0,2634 & $-0,1365$ & 0,1488 & 2,2985 & 2,6637 & 0,9005 & 0,1668 & $-2,5993$ & 0,3606 \\
\hline 2004-2003 & 7,5680 & $-9,2636$ & 1,3524 & 0,1377 & 1,0160 & 1,5761 & 0,4466 & $-0,4885$ & $-0,0318$ & 1,2497 & 0,6774 & 0,4567 \\
\hline 2005-2004 & 3,7790 & 29,8286 & 0,2920 & 0,0758 & $-0,3509$ & 2,4409 & 1,0770 & $-0,3575$ & $-0,5299$ & $-0,1880$ & $-6,3858$ & 0,7999 \\
\hline 2006-2005 & 3,3219 & 9,2318 & $-1,4077$ & 0,5002 & 0,1058 & 0,5018 & 0,5544 & 3,1506 & $-0,0157$ & 0,1123 & 3,8132 & $-0,0541$ \\
\hline $2007-2006$ & 2,1198 & 3,1753 & 0,8654 & 0,7394 & $-0,2309$ & $-0,4370$ & 1,3408 & 0,8986 & 0,1658 & 0,1549 & 3,6726 & $-0,5795$ \\
\hline 2008-2007 & 0,0324 & 4,3946 & $-0,0080$ & 0,4137 & 0,9218 & 1,4522 & 0,0687 & 0,3619 & 0,6452 & 0,0298 & 2,9127 & $-0,2840$ \\
\hline 2009-2008 & $-0,1369$ & 3,4541 & $-0,1652$ & 0,5271 & 1,3921 & 0,4703 & $-0,4838$ & 1,0071 & 0,8222 & 0,1105 & 3,8811 & 1,5269 \\
\hline 2010-2009 & 0,4033 & 2,2293 & 1,1420 & 0,5641 & 0,7448 & 0,1135 & $-0,0187$ & 1,6876 & 0,9272 & 0,2341 & 3,1183 & 0,2784 \\
\hline 2011-2010 & 0,2930 & 2,8722 & 1,0553 & 0,5687 & 1,2603 & 0,8048 & 1,0639 & $-0,2854$ & $-0,0107$ & 0,2335 & 0,7357 & 1,7632 \\
\hline
\end{tabular}
Source: Own elaboration.

In 1994-1993 and 1999-1998 there are negative variations, and more significant, in Austria followed by Turkey in the first period, while in the second period mentioned it is Belgium 
followed by Austria and Turkey, respectively, which present the highest negative variations of this EF effect. Denmark presents the highest positive variation in this effect. During the 2000 decade we need to register in the period 2002-2001 the highest negative variation of EF which occurs in Belgium and Austria, in this order, and the highest positive one in Turkey. In 2003-2002 it is still verified a tendency for higher negative variations occurring in Belgium but now followed by Turkey, while in 2006-2005 and in 2011-2010 there exists a tendency for positive variations in the three economies, Belgium, Turkey and Austria, respectively. We need to also notice that in 2009-2008 although there is still is a positive change in EF in Turkey and Belgium, by opposition in Austria we assist to a higher negative variation with respect to all other countries in this European sub group.

In this period, we also had interest in extending our analysis to the sub group of countries which are in the Top ranking of renewable sources outside Europe. Namely, we analyze also in the rest of the work $\mathrm{CO}_{2}$ emissions decomposition for the Rest of the World countries inside the Top 23. These are Australia, Brazil, Canada, Chile, Indonesia, Japan, Kenya, Mexico, Peru, Philippines and United States. 
Figure 3 - Top renewable energy Rest of the World group of countries $-\mathrm{CO}_{2}$ emissions LMDI decompositions and $\mathrm{CO}_{2}$ emissions changes

Top Rest of the World countries

80

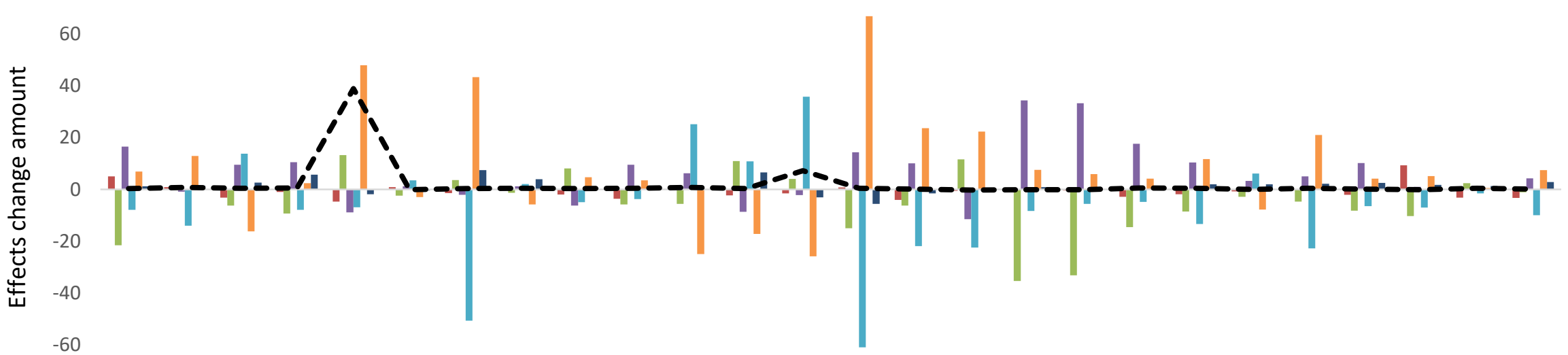

$-80$

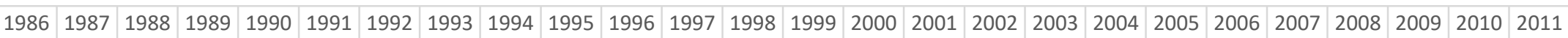
\begin{tabular}{llllllll|l|l|l|l|l|l|l|l|l|l|l|l|l|l|l|l|l|l}
5.001 & 0.894 & -3.21 & -0.95 & -4.66 & 0.854 & -1.36 & 0.215 & -1.96 & -3.65 & -0.22 & -2.3 & -1.48 & 0.736 & -4.07 & -0.56 & 0.645 & -0.44 & -2.88 & -1.85 & -0.8 & -0.31 & -2.04 & 9.304 & -3.15 & -3.31 \\
\hline
\end{tabular}

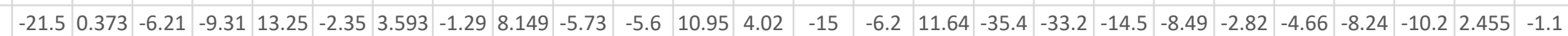

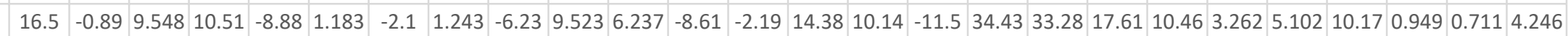

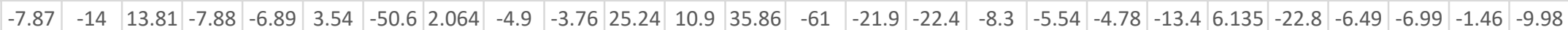

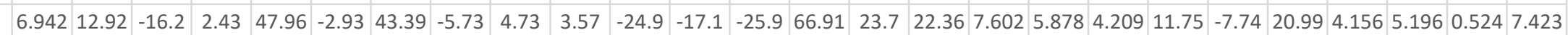

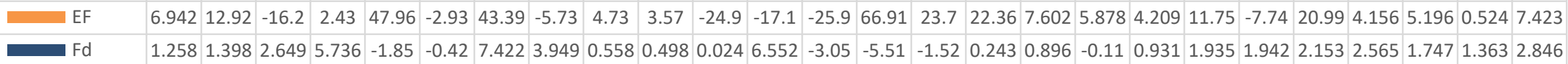

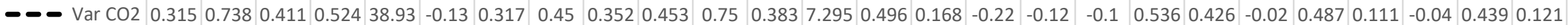

$\mathrm{Cl}=\mathrm{Fl} \longrightarrow \mathrm{RP}=\mathrm{Fd}$

Note: CI denotes carbon trade intensity, TF the trade of fossil fuels effect, FI fossil fuels intensity, RP renewable sources productivity, EF electricity financial power effect, Fd the financial development effect; Var $\mathrm{CO} 2$ stands for $\mathrm{CO} 2$ emission changes between $\mathrm{t}$ and $\mathrm{t}-1$ due to the six considered effects. 
In accordance to Figure 3 we may observe that there exists high variability in $\mathrm{CO}_{2}$ emission changes, by opposition to what happened in the European sub group. So, we need to register here that the greatest positive change in carbon emissions occurred in the year 1990 in face of 1989 (see Table A.3 at the appendix for the values here registered) of 38.9 ton. For this amount we had the positive contribution of the change in effects EF (123\%) and of TF (34\%) which have annulated the impact of the negative change of effects FI (23\%) and of the RP effect (18\%). It was followed by a new period with a second positive variation in carbon emissions of 7.29 ton, with special relevance for the impact of the change of the RP effect of $492 \%$ which has compensated the negative impact of the EF effect of $335 \%$.

It is noticed from Figure 3 that $\mathrm{CO}_{2}$ emission changes have two positive increases in this set of the Rest of the World countries, followed by sudden drops, in the periods 1989-1991 and a lower one in the period 1997-1999. Although there are in other time periods a positive change in carbon emissions, these are not so expressive. As such, we will highlight in the last years the carbon changes of 0.43 ton and of 0.12 ton. In 2010 with respect to 2009 we register the positive contribution for emission changes the positive and significant in magnitude effect of TF (55.9\%). This has compensated the impact of the negative change of the RP effect of 33.3\%. In the period 2011-2010 the contribution for changes of the EF effect (61.19\%) and that of the FI effect (30.5\%) have compensated the negative RP impact effect of $82.3 \%$, thus allowing for a positive change in emissions.

The negative changes, and not so significant in magnitude, of carbon emission changes in this sub group of countries occurred mostly in the 2000 decade, given that in the previous one there was only one registration of a lower negative occurrence in emissions of 0.13 ton in 1991-1990. Here the impact of the negative change occurred in the TF effect of $18.1 \%$ and in the effect EF of $22.6 \%$ has compensated the positive one happening in the RP effect of $27.3 \%$. In turn, in years 2001 until 2003 the small emission changes in the amount of 0.225 ton in 2001, 0.117 ton in 2002 and 0.095 in 2003 are explained by the negative changes occurred in the RP effect and in FI which have compensated the positive changes occurred in EF and TF.

We need to stress in 2002 and 2003 the strong negative impact of TF of 301\% and 347\%, respectively, which have compensated the positive FI impact of $293 \%$ and $348 \%$, respectively. Afterwards in 2006 we see a reduced change in emissions of 0.022 ton due to the negative change in EF of $345.7 \%$, compensating the positive impact of the RP change of $273 \%$. Finally in 2009 a reduced change in emissions of 0.04 ton is explained through the 
negative contribution of changes in TF (255\%) and RP (173.8\%), which have compensated the positive ones in CI of $231 \%$ and those of EF of $129 \%$.

Next we will analyze for this sub group of non-European countries the contributions of the main effects throughout the period considered considering the disaggregated impact of each of the most relevant effects noticed, as previously, of FI, RP and EF, at each country level and year, in the countries belonging to the Rest of the World in our sample.

Table 5 - FI factor decomposition and impact by years for each of the Rest of the World subgroup countries

\begin{tabular}{|c|c|c|c|c|c|c|c|c|c|c|c|}
\hline$\Delta \mathrm{FI}$ & Australia & Brazil & Canada & Chile & Indonesia & Japan & Kenya & Mexico & Peru & Philippines & United States \\
\hline 1986-1985 & 0,1767 & 4,9554 & $-0,4195$ & $-0,6904$ & 0,5749 & $-0,0391$ & 10,9582 & 0,5679 & 0,9194 & $-0,4404$ & $-0,0648$ \\
\hline 1987-1986 & 0,2423 & $-1,6746$ & 0,7294 & $-0,1393$ & 0,5042 & 0,1960 & $-2,8597$ & 0,4668 & 1,3740 & 0,1643 & 0,1111 \\
\hline 1998-1987 & 0,2700 & $-0,8253$ & 0,4454 & 5,3666 & 0,6019 & 0,1807 & 2,9910 & 0,1081 & $-0,0464$ & 0,3506 & 0,1051 \\
\hline 1989-1988 & 0,2096 & $-0,1152$ & 0,4242 & 3,7868 & $-0,2256$ & 0,2141 & 4,6303 & 0,1957 & 0,5011 & 0,6721 & 0,2137 \\
\hline 1990-1989 & 0,2133 & $-1,0278$ & $-0,6647$ & $-0,3010$ & 1,0309 & 0,2274 & $-6,2591$ & $-0,1864$ & $-1,8870$ & $-0,0041$ & $-0,0211$ \\
\hline 1991-1990 & 0,0186 & 0,7817 & 0,1289 & $-1,4034$ & 0,3152 & 0,0345 & 3,3970 & 0,1689 & $-2,1747$ & $-0,0837$ & 0,0000 \\
\hline 1992-1991 & 0,0844 & 0,5280 & 0,2711 & $-7,8054$ & 0,0689 & 0,0711 & 0,6159 & $-0,0732$ & 4,0324 & 0,0827 & 0,0225 \\
\hline 1993-1992 & 0,0476 & $-0,0357$ & $-0,3561$ & 1,8654 & 0,4981 & $-0,1799$ & 0,8530 & 0,1835 & $-1,7072$ & $-0,0274$ & 0,1021 \\
\hline 1994-1993 & 0,0819 & $-0,0268$ & 0,0631 & 4,1834 & 0,5745 & 0,3754 & $-3,9349$ & 0,6927 & $-9,9345$ & 1,6751 & 0,0209 \\
\hline 1995-1994 & 0,1312 & 1,0513 & 0,2846 & 2,4550 & $-0,2617$ & $-0,0852$ & $-8,7634$ & $-0,2001$ & 14,0002 & 0,9008 & 0,0101 \\
\hline 1996-1995 & 0,0800 & 1,3570 & $-0,0798$ & 3,1482 & 0,5873 & 0,0344 & 0,3629 & 0,2004 & 0,0287 & 0,4811 & 0,0369 \\
\hline 1997-1996 & 0,0754 & 0,9059 & 0,4819 & 1,3939 & 0,9404 & $-0,0085$ & $-15,8284$ & 0,4574 & 2,1577 & 0,7486 & 0,0689 \\
\hline 1998-1997 & 0,2776 & 0,3417 & 0,4711 & 2,1257 & $-0,1221$ & $-0,0217$ & $-5,9816$ & 0,2367 & 0,1615 & 0,2182 & 0,1019 \\
\hline 1999-1998 & 0,0784 & 2,4423 & $-0,0252$ & 1,4532 & 0,4441 & 0,1412 & 11,6809 & 0,0202 & $-0,7522$ & $-1,0903$ & $-0,0097$ \\
\hline 2000-1999 & 0,1133 & 0,1709 & 0,3140 & $-0,8828$ & 0,3484 & $-0,0889$ & 11,6944 & 0,2821 & $-2,5969$ & 0,6783 & 0,1032 \\
\hline $2001-2000$ & 0,2465 & 1,1238 & 0,1061 & $-0,3776$ & 0,2615 & $-0,0766$ & $-11,0410$ & 0,2821 & $-2,7302$ & 0,7108 & $-0,0237$ \\
\hline $2002-2001$ & 0,0335 & $-0,3060$ & $-0,1427$ & $-0,0143$ & 0,3993 & 0,2259 & 30,4686 & 0,1533 & 3,2907 & 0,2746 & 0,0427 \\
\hline 2003-2002 & $-0,0564$ & $-0,3563$ & 0,0268 & 1,0565 & 0,2881 & 0,1354 & 30,1565 & 0,0190 & 1,4047 & 0,5970 & 0,0088 \\
\hline 2004-2003 & 0,1457 & 1,2952 & $-0,2295$ & 0,8212 & 0,1665 & $-0,0788$ & 9,8463 & 0,2782 & 5,0974 & 0,2251 & 0,0394 \\
\hline 2005-2004 & $-0,1861$ & $-0,1179$ & 0,0107 & $-0,6935$ & 0,2220 & 0,0501 & 9,9203 & 0,0946 & 0,9710 & 0,1256 & 0,0589 \\
\hline 2006-2005 & 0,0292 & $-0,0408$ & $-0,3228$ & 0,0982 & 0,2248 & $-0,0389$ & 3,9664 & 0,0460 & $-0,3570$ & $-0,3001$ & $-0,0431$ \\
\hline $2007-2006$ & 0,1597 & $-0,3413$ & 0,2581 & 1,4895 & 0,2156 & 0,3566 & $-0,3911$ & 0,1696 & 2,5606 & 0,5355 & 0,0894 \\
\hline 2008-2007 & $-0,0033$ & 2,0771 & $-0,2183$ & $-0,0691$ & 0,1309 & $-0,1944$ & 6,5848 & $-0,1282$ & 2,1502 & $-0,1004$ & $-0,0603$ \\
\hline 2009-2008 & 0,0970 & $-2,2745$ & $-0,3205$ & $-0,2301$ & 0,1352 & $-0,2164$ & 3,8493 & 0,2284 & $-0,3198$ & 0,1799 & $-0,1789$ \\
\hline 2010-2009 & $-0,0075$ & 2,6689 & 0,0902 & 0,7519 & 0,1530 & 0,1404 & $-5,1627$ & 0,0289 & 1,0959 & 0,8128 & 0,1393 \\
\hline 2011-2010 & $-0,0718$ & $-0,3194$ & 0,1584 & 0,4525 & 0,4376 & 0,4955 & 2,2769 & 0,3187 & 0,6856 & $-0,0819$ & $-0,1057$ \\
\hline
\end{tabular}

Source: Own elaboration.

In accordance to Table 5, the intensity of fossil fuel resources in electricity generation (FI effect), in this sub group of countries emerge those of Kenya, Peru, Chile and Brazil as countries where this effect presents results with higher evidence of temporal change. More 
specifically in 1986-1985 and in 1989-1988 we observe that in Kenya there was a higher positive change of this effect, followed by Chile. Chile and Brazil present the highest negative variations, respectively, by periods and with respect to the rest of the changes registered for this sub group. In turn, in 1990-1989, in 1994-1993, in 1997-1996 and in 19981997 we verify successively in these periods and for this FI effect that Kenya presents the highest negative variability and that Peru and Chile alternate their position between them with respect to the positive change. In 2000-1999 it is Kenya and Peru which present the highest negative variation in the FI effect and in the subsequent periods of 2002-2001 until 2008-2007, except in 2007-2006 and the year 2010-2009, Kenya and Peru present the highest positive changes of the FI effect.

Table 6 - RP factor decomposition and impact by years for each of the Rest of the World subgroup countries

\begin{tabular}{|c|c|c|c|c|c|c|c|c|c|c|c|}
\hline$\Delta \mathrm{RP}$ & Australia & Brazil & Canada & Chile & Indonesia & Japan & Kenya & Mexico & Peru & Philippines & United States \\
\hline 1986-1985 & 0,3365 & $-0,6549$ & $-3,8707$ & 4,4087 & $-0,2457$ & $-0,3347$ & $-5,2372$ & $-2,4314$ & 0,6818 & $-0,0791$ & $-0,4426$ \\
\hline $1987-1986$ & 5014 & $-1,7323$ & $-6,0299$ & $-0,5633$ & $-7,3373$ & $-0,2980$ & 0,4332 & $-0,7173$ & 0,9788 & 0,9133 & $-0,1089$ \\
\hline 1998-1987 & 15,8092 & 1,0335 & $-1,5494$ & 2,6359 & $-3,1232$ & $-0,0682$ & $-0,2911$ & $-0,4934$ & 0,0677 & $-0,2940$ & 0,0867 \\
\hline 1989-1988 & 6,3615 & $-0,2829$ & $-6,4377$ & $-0,3340$ & $-0,3422$ & $-0,0224$ & $-0,0513$ & $-0,2316$ & $-0,4232$ & $-0,2982$ & $-5,8221$ \\
\hline 1990-1989 & $-4,8580$ & $-1,9513$ & $-2,0142$ & 1,3812 & 0,4532 & 1,3965 & $-0,0049$ & $-0,7044$ & 0,4342 & 0,0088 & $-1,0266$ \\
\hline 1991-1990 & 1,4918 & $-0,4986$ & $-0,1226$ & 1,3799 & 1,0341 & $-0,1612$ & 0,1656 & $-0,9138$ & $-0,1911$ & 0,1611 & 1,1952 \\
\hline 1992-1991 & $-7,0298$ & $-2,6582$ & $-1,7812$ & $-38,1954$ & $-0,8241$ & 0,0221 & 0,1233 & $-0,8680$ & 0,4536 & 0,3679 & $-0,2330$ \\
\hline 1993-1992 & 0,7353 & $-0,1175$ & $-0,9916$ & 0,8548 & 1,1828 & $-0,2945$ & $-0,0761$ & $-0,1595$ & 1,0709 & $-0,1033$ & $-0,0372$ \\
\hline 1994-1993 & 0,4203 & $-0,9411$ & $-2,0278$ & $-1,0578$ & $-2,7135$ & 0,0585 & 1,1672 & 1,2048 & $-0,6616$ & $-0,3354$ & $-0,0126$ \\
\hline 1995-1994 & 2160 & $-0,3955$ & 0,2021 & $-3,5152$ & $-0,4713$ & $-0,7291$ & $-1,0026$ & $-1,3336$ & $-1,1637$ & 4156 & 0,0201 \\
\hline 1996-1995 & 24,1560 & $-2,0147$ & $-0,4028$ & 2,8825 & 0,0555 & $-0,1955$ & $-0,0268$ & 0,5497 & 0,4733 & $-0,1717$ & $-0,0683$ \\
\hline 1997-1996 & 11,1018 & $-0,8742$ & $-1,7400$ & 0,0553 & 1,6551 & $-0,4015$ & 0,5728 & 0,7443 & $-0,4748$ & 0,0364 & 0,2291 \\
\hline $1998-1997$ & 11,1153 & $-0,1651$ & $-0,5895$ & 27,0398 & $-2,4196$ & $-0,0426$ & $-0,1041$ & 0,2344 & 1,3878 & $-0,7146$ & 0,1215 \\
\hline 1999-1998 & $-43,9194$ & $-1,0007$ & $-1,3087$ & $-13,3733$ & 0,3899 & 0,1168 & 1,0222 & $-0,4329$ & $-0,9301$ & $-1,3503$ & $-0,2097$ \\
\hline 2000-1999 & $-4,5859$ & 0,6685 & 0,0172 & $-13,3808$ & $-3,0734$ & 0,0748 & $-0,4269$ & 0,2232 & $-1,2884$ & $-0,1386$ & 0,0299 \\
\hline $2001-2000$ & $-19,9303$ & $-1,2994$ & $-0,4753$ & 1,6505 & $-1,3166$ & $-0,0514$ & $-1,6166$ & 0,1708 & $-0,4899$ & 0,7568 & 0,2074 \\
\hline $2002-2001$ & $-8,4819$ & 342 & 988 & 1,6477 & 0,5600 & 0,0264 & 0847 & 4337 &, 6173 & 0,2205 & $-0,3726$ \\
\hline $2003-2002$ & $-4,8860$ & $-1,2354$ & $-0,3801$ & 2,2841 & 0,4580 & 0,0267 & $-1,9047$ & $-0,1160$ & $-0,1707$ & 0,3665 & 0,0207 \\
\hline 2004-2003 & $-2,2930$ & $-0,3249$ & 0,1342 & $-3,2885$ & $-0,2621$ & $-0,3944$ & $-0,3152$ & $-0,2085$ & 2,4245 & $-0,1203$ & $-0,1337$ \\
\hline $2005-2004$ & $-9,7979$ & $-0,6358$ & $-0,8222$ & 3,6201 & 0,0856 & $-0,5144$ & 0,2850 & $-0,7354$ & $-5,0020$ & 0,2682 & $-0,1159$ \\
\hline 2006-2005 & $-2,1577$ & $-0,6393$ & $-0,3241$ & 9,2655 & 0,4736 & $-0,2357$ & 0,0826 & 0,5064 & $-0,0352$ & $-0,4703$ & $-0,3308$ \\
\hline $2007-2006$ & $-1,7003$ & $-1,5159$ & $-0,1940$ & $-19,1336$ & 019 & 0,2481 & $-0,0324$ & $-0,0197$ & $-0,4054$ & 0,5220 & $-0,1501$ \\
\hline $2008-2007$ & $-1,5986$ & $-0,6333$ & 0,4453 & $-2,5117$ & $-0,8324$ & 0,0802 & 0,0274 & $-0,6324$ & 0,0609 & $-0,3417$ & $-0,5568$ \\
\hline 2009-2008 & 1,3911 & $-0,9373$ & $-2,3143$ & $-4,7780$ & $-0,4294$ & $-0,3620$ & 0,1133 & 0,6707 & $-0,0310$ & 0,2467 & $-0,5563$ \\
\hline 2010-2009 & $-1,7698$ & $-1,9968$ & $-1,5292$ & 8,3419 & $-0,7249$ & $-1,3124$ & $-0,9261$ & $-0,4930$ & $-1,6006$ & 0,8559 & $-0,3071$ \\
\hline 2011-2010 & $-0,7463$ & $-0,2729$ & $-0,6374$ & $-9,7277$ & 1,1645 & 0,7411 & 0,0685 & 0,1389 & 0,1076 & $-0,2814$ & $-0,5330$ \\
\hline
\end{tabular}

Source: Own elaboration. 
In accordance to Table 6, the renewable resources productivity impact in electricity generation, the RP effect, is one of the most important with respect to the magnitude significance level of negative changes occurred in carbon emission changes, especially in Australia and Chile in the entire period of analysis and for Indonesia and Canada before the 2000 decade.

More specifically, in the year 1987-1986 there exists a contribution in the sense of a negative change in renewable resources productivity, more significant in Indonesia and in Canada. In 1988-1987 there is a positive change in Australia and Chile, while in 1989-1988 Canada presents a higher negative variation in renewables productivity as in Indonesia. Already in 1992-1991 there is the predominance of a negative variation of this RP effect in these four economies, with Chile presenting the highest variation and right after Australia. In the subsequent years 1996-1995, 1997-1996 and 1998-1997 there exists a positive change in this same productivity for Australia and Chile with higher impact in Australia except in 19981997, where Chile presents the highest one. By opposition, in 1999-1998 and in the two subsequent periods of negative variation, there is an inversion in renewables productivity with Australia and Chile altering the two primary positions respectively. This tendency of negative variation will be kept along the other subsequent periods for Australia, with predominance of being the main country where it happened a negative change. This, except in the 2007-2006 and 2011-2010 periods, where Chile presents itself as the country where the highest negative variation happened in renewable resources productivity used. Besides, in these same periods whereas Australia emerges with the biggest negative variation, Chile is the country with the highest positive variation in the RP effect.

With respect to the importance of the EF effect and in accordance with results presented by Table 7, the behavior of this effect seems to not being dissociated from the impact of the renewable resources productivity effect to explain emissions changes occurred. We highlight the importance of these two effects in Australia and Chile in most of the sample period considered, and the countries Indonesia and Canada before the 2000 decade, as already mentioned previously.

More specifically in 1988-1987 and in 1989-1988 we observe that Australia and Chile and that in Australia and Indonesia we have higher negative variations respectively for these periods. In 1992-1991 there exists a positive change in this effect for the four economies with Chile and Australia presenting the higher variations followed by Indonesia and Canada. This same behavior tendency is observed in 1999-1998. In this decade intermediate periods, 
1996-1995, 1997-1996 and 1998-1997, Australia and Chile presented continuously a negative change in the EF effect with Canada presenting a positive variation in these same periods, and with respect to all other economies considered in this sub group. Along the almost entire 2000 decade, Australia revealed a more positive variation and significant in magnitude in the EF effect while Chile reveals a negative variation, except in 2009-2008 and 2010-2009 where we observe a behavior inversion. This even if in the 2007-2006 and 20112010 periods these two economies presented the same positive signal in this effect change and with respect to all other economies considered in the Rest of the World sample of countries sub group.

Table 7 - EF factor decomposition and impact by years for each of the Rest of the World subgroup countries

\begin{tabular}{|c|c|c|c|c|c|c|c|c|c|c|c|}
\hline$\Delta \mathrm{EF}$ & Australia & Brazil & Canada & Chile & Indonesia & Japan & Kenya & Mexico & Peru & Philippines & United States \\
\hline 1986-1985 & $-0,7835$ & $-1,2119$ & 3,8171 & $-4,0034$ & $-0,9109$ & 0,1627 & 5,4191 & 2,4217 & $-0,0314$ & 1,9064 & 0,1566 \\
\hline $1987-1986$ & $-0,8092$ & 1,6984 & 5,9644 & 0,9277 & 6,9497 & $-0,1248$ & $-0,2335$ & 0,7791 & $-0,8702$ & $-1,3714$ & 0,0084 \\
\hline 1998-1987 & $-16,2559$ & $-3,0705$ & 1,4375 & $-2,2665$ & 2,3818 & $-0,1350$ & 0,0056 & 1,6823 & $-0,0696$ & 0,2366 & $-0,1313$ \\
\hline 1989-1988 & $-7,5250$ & $-0,7796$ & 6,1769 & 0,6591 & $-0,7952$ & $-0,1431$ & $-0,0279$ & $-2,3345$ & 1,6944 & $-0,1599$ & 5,6645 \\
\hline 1990-1989 & 4,7539 & 6,9353 & 1,8122 & 37,9934 & $-2,2064$ & $-1,4896$ & $-0,1750$ & $-0,1006$ & $-0,0605$ & $-0,6369$ & 1,1372 \\
\hline 1991-1990 & $-1,4547$ & 0,1400 & $-0,0147$ & $-1,1030$ & $-0,9439$ & 0,1490 & $-0,3094$ & $-0,2912$ & 1,9638 & 0,3023 & $-1,3717$ \\
\hline 1992-1991 & 6,8966 & $-0,2645$ & 1,6949 & 37,9288 & 1,0146 & $-0,1067$ & $-0,2627$ & $-0,9332$ & $-1,6053$ & $-1,2419$ & 0,2712 \\
\hline 1993-1992 & $-0,8404$ & $-1,7893$ & 1,0536 & $-1,2390$ & $-1,5565$ & 0,2454 & 0,8706 & 0,7540 & $-1,8776$ & $-1,2816$ & $-0,0700$ \\
\hline 1994-1993 & $-0,6678$ & 3,8159 & 2,0971 & 1,1651 & 2,4197 & $-0,1059$ & $-1,1771$ & $-2,3676$ & $-0,3122$ & $-0,1813$ & 0,0440 \\
\hline 1995-1994 & $-4,4215$ & 2,6712 & $-0,1564$ & 3,3647 & 0,3217 & 0,7356 & 0,2471 & 2,7471 & 0,1670 & $-1,7173$ & $-0,3888$ \\
\hline 1996-1995 & $-24,2651$ & 2,2600 & 0,1738 & $-3,2605$ & $-0,2309$ & 0,1723 & 1,1816 & 2,3464 & $-2,0170$ & $-1,0992$ & $-0,1869$ \\
\hline $1997-1996$ & $-11,3394$ & 0,8643 & 1,5617 & $-0,9975$ & $-2,1046$ & 0,1727 & $-0,7434$ & $-3,0452$ & $-0,2937$ & $-0,6823$ & $-0,5116$ \\
\hline 1998-1997 & $-4,4402$ & 1,9557 & 0,6532 & $-27,0210$ & 3,0716 & $-0,1346$ & 0,2094 & 0,4485 & $-2,0962$ & 1,9416 & $-0,4539$ \\
\hline 1999-1998 & 43,6427 & 0,9467 & 1,3293 & 13,4003 & 5,0032 & $-0,1695$ & $-1,3494$ & 1,5355 & 0,8097 & 1,9223 & $-0,1585$ \\
\hline 2000-1999 & 4,4056 & $-0,9244$ & 0,1440 & 13,4078 & 3,2950 & 0,0717 & 0,5646 & 0,3678 & 1,7922 & 0,3701 & 0,2075 \\
\hline 2001-2000 & 19,8886 & 1,4871 & $-2,0901$ & $-1,7287$ & 1,1916 & 0,6253 & 2,2038 & 0,9166 & 1,1458 & $-0,8593$ & $-0,4222$ \\
\hline 2002-2001 & 8,3391 & 1,0727 & 0,6133 & $-1,7257$ & $-0,8690$ & 0,0280 & $-0,0395$ & $-1,4874$ & 0,9244 & 0,1478 & 0,5981 \\
\hline 2003-2002 & 4,5323 & 1,6430 & 0,5257 & $-2,3350$ & $-0,9413$ & $-0,0166$ & 2,1499 & 0,0169 & 0,8130 & $-0,1035$ & $-0,4060$ \\
\hline 2004-2003 & 457 & 473 & $-0,1999$ & 315 & $-0,6010$ & 0,5482 & $-0,0998$ & 0,5430 & $-1,8260$ & 0,2631 & $-0,0433$ \\
\hline 2005-2004 & 9,5630 & 0,1866 & 0,6401 & $-3,6617$ & $-0,0937$ & 0,1982 & $-0,1265$ & 0,1734 & 4,5618 & 0,2797 & 0,0254 \\
\hline 2006-2005 & 1,9707 & $-0,7213$ & $-0,0155$ & $-9,3387$ & $-0,0375$ & 0,3124 & 0,5811 & $-1,7343$ & 0,5857 & 0,5409 & 0,1123 \\
\hline 2007-2006 & 1,4552 & 0,6439 & 1,8749 & 18,8215 & 0,1936 & $-0,0502$ & $-0,0187$ & $-0,6994$ & $-0,6444$ & $-0,5537$ & $-0,0301$ \\
\hline 2008-2007 & 1,5611 & 0,1241 & $-0,4611$ & 1,7995 & 0,5766 & 0,0501 & $-0,5375$ & 0,8653 & $-1,0778$ & 0,3044 & 0,9513 \\
\hline 2009-2008 & $-1,4246$ & 1,3696 & 1,2982 & 4,6918 & 0,1858 & 0,1546 & $-0,0416$ & $-1,2455$ & 0,1051 & $-0,2648$ & 0,3677 \\
\hline 2010-2009 & 1,6647 & 1,4734 & 1,5712 & $-8,2213$ & 0,8128 & 1,5007 & 0,5029 & 0,0790 & 1,6378 & $-0,9320$ & 0,4351 \\
\hline 2011-2010 & 0,8425 & $-0,2054$ & 0,6694 & 9,6356 & $-1,7436$ & $-0,7161$ & $-0,6328$ & $-0,4845$ & $-0,5520$ & $-0,1153$ & 0,7249 \\
\hline
\end{tabular}

Source: Own elaboration. 
To reinforce the conclusions taken we will finish this section discussion with a decoupling analysis of the decoupling between $\mathrm{CO}_{2}$ emissions, economic growth and the relationship with renewable energy consumption. In the sustainability literature, decoupling has deserved special attention [63] allowing us to take conclusions about the relationship between two or more interdependent variables. It refers to the reduction of a country carbon emissions without causing negative impacts over that country economic growth. We believe that the sustainability analysis on renewable energies requires also the understanding of the decoupling of economic growth from resources consumption (resource decoupling) and environmental degradation (impact decoupling).

Analyzing decoupling between carbon emissions, growth and influencing factors allows to see which of the effects contributes more to emissions reduction while keeping economic growth, in terms of elasticity effects. As such, we have also considered in this last step, the study of the decoupling relationship considering all countries in the sample in an individual way (see the different decoupling states considered by Tapio in table A.5 at the appendix) and for three distinct periods $(1986-1994 ; 1995-2004 ; 2005-2011)$. According to Figures A.1, A.2 and A.3 and table A.4 in the appendix, the optimal state of strong decoupling was showed for France, Norway, Sweden and United Kingdom in the first period 1986-1994, for Belgium, Denmark, Sweden and United Kingdom in the second period change 1995-2004, while in last period 2005-2011, in similar situation were Austria, Belgium, Canada, Denmark, France, Indonesia, Japan, Netherlands, Portugal, Spain, Sweden, United Kingdom and United States. That decoupling state occurs with negative decoupling elasticity, meaning that the economic growth measure, the GDP rate (positive), is accompanied by a corresponding negative $\mathrm{CO}_{2}$ emissions growth rate.

Moreover, the results of the analysis of the decoupling of the $\mathrm{CO}_{2}$ emissions in terms of GDP shows an expansive decoupling with decoupling index (elasticity) higher than 1.2 (for the reference value see Table A.5) for Brazil, Chile, Indonesia, Kenya, Peru, Philippines, Portugal and Turkey in the first period (1986-1994), while in the second period (1995-2004), this state of decoupling is observed in Austria, Brazil, Chile, Indonesia, Italy, Norway, Peru, Portugal, Spain and Turkey. For the period after the first Kyoto commitment (2005-2011), Brazil, Chile, Kenya, Norway, Peru and Turkey show that expansive decoupling state. In summary, for all the three periods analyzed, only the countries Brazil, Chile, Peru and Turkey show an expansive decoupling. This means that the economic growth measure, the 
GDP rate (positive), was accompanied by a corresponding positive $\mathrm{CO}_{2}$ emissions growth rate, and so growth was achieved at the expense of more emissions.

We are able to observe a recession decoupling state for Italy in the last period of 2005-2011, where a negative change of the GDP rate is accompanied by a corresponding negative change of $\mathrm{CO}_{2}$ emissions rate and that the decoupling elasticity is higher than 1.2 , meaning that emissions reduction is done at the cost of lower growth. We find a weak decoupling for the 1986-1995 period in Australia, Austria, Belgium, Canada, Denmark, Italy, Netherlands, Spain and United States; for the second period in Australia, Netherlands and the United States and for the last period of 2005-2011, in only Australia and the Philippines, where the decoupling index ranged between 0 and 0.8. That weak decoupling is based on a good positive change of the GDP rate being accompanied by a corresponding positive change of the $\mathrm{CO}_{2}$ emissions rate, and as such countries grew but this growth lead to more emissions. We also find a growing link in the period 1986-1994 for Japan and Mexico, in the 19952004 period for Canada, France, Japan, Mexico and Philippines, and in the last period 20052011 for Mexico, where the decoupling elasticity ranges between 0.8 and 1.2. In this decoupling state we have simultaneously a positive change of the GDP rate and a positive change of the rate of $\mathrm{CO}_{2}$ emissions.

Figures A.1 and A.2 in the appendix show that, for France, Norway and Sweden in the first period 1986-1994, and for Belgium, Denmark and United Kingdom in the second period 1995-2004, the average rate of increased change of renewable energy played a positive and slow effect in decreasing $\mathrm{CO}_{2}$ emissions, whose effect is associated to an economic growth change. These crossed effects played an important role in the occurrence of strong decoupling. The increase of the rate of renewable energy was the main reason that led to the occurrence of strong decoupling, whose average value of elasticity was higher than 1.2. This impact may be attributed to the slow economic growth and to the quick correspondent slow decrease in $\mathrm{CO}_{2}$ emissions. As we may observe in these two analyzed periods, the optimal expected situation of strong decoupling was verified only for these European countries. Not less important is the fact that for the Rest of the World countries, Chile for 1986-1994 and Australia for 1995-2004, have presented the highest average growth rates of renewable energy penetration of $74.98 \%$ and $98.44 \%$, respectively in each of the periods. This situation was associated to a very low average rate of economic growth and to a very low average emissions growth rate, meaning the presence of the growing link state or of expansive decoupling (the elasticity index changing between the values 0.8 and 1.2). 
In the last change period considered of 2005-2011, the average rate of increase of renewable energy (80.28\%) in Belgium played a positive and slow effect in decreasing $\mathrm{CO}_{2}$ emissions, whose effect is associated to a smallest economic growth change; these crossed effects played an important role in the occurrence of the strong decoupling state in Belgium. It is shown a clear evidence of different adaptation velocities to challenges and compromises with respect to the adherence to renewable energies into two distinct groups of countries. The decomposition and coupling results indicate that, from one side economic growth appeared as the main driver of carbon emission increases in the past decades in the sample of the European and for the Rest of the World countries, while the decrease of energy intensity, the clearing of the final energy consumption structure and renewable energy productivity played significant roles in terms of mitigation, with different velocities, and in explaining the behavior of carbon emissions verified. It is shown a clear evidence of different adaptation velocities to challenges and compromises with respect to the adherence to renewable energies into the two distinct groups of countries.

\section{Conclusions}

This paper main purpose was to decompose and afterwards decouple the changes of $\mathrm{CO}_{2}$ emissions yearly form 1985 to 2011 into their most influential factors for the top 23 countries, ranked by their use of renewable energies. To do so, we employed the LMDI method in order to decompose emissions into the following six factors: carbon trade intensity (CI), trade fossil fuels effects (TF), fossil fuels intensity (FI), renewable source productivity (RP), electricity financial power effect (EF) and financial development effect (Fd). The reason for selecting the specific group of countries is firstly to identify the driving factors of their emissions even though they have selected a renewable energy path, to inform policy makers but also, to derive valuable lessons for other countries that aim at increasing the share of renewable energies to their total supply mix. In the meanwhile, we introduced the decoupling index to analyze the decoupling relationship between $\mathrm{CO}_{2}$ emissions and economic growth to complement the results of the decomposition application.

Appreciating that in the group of the top 23, two sub-groups emerged due to its geographical position, general natural resources and policy approaches, we proceeded to estimate the results for the European countries separately from the Rest of the world country group. All in all, the results show that the most contributing factors are not static and constant throughout the years. Differences from year to year are observed both for the top 23 as a 
whole, as well as for the European and Rest of the World sub-groups. This observation should be taken seriously into account by policy makers that must aim for flexible and adjustable policies and measures for the reduction of emissions. For the total group, and for most of the years, the electricity financial power effect (EF) was the contributing factor to the increase in $\mathrm{CO}_{2}$ emissions in countries; while, the renewable sources productivity (RP) contributed towards a decrease in $\mathrm{CO}_{2}$ emissions for most years.

The same factors seem to be decisive for the country sub-group of the rest of the world: EF towards rising $\mathrm{CO}_{2}$ and RP towards decreasing them. The energy intensity effect captures the substitution of fossil fuels for cleaner types of electricity generation. In order to understand this change in sign in Kenya, Peru, Chile and Brazil we should consider two key factors that may also be observed in energy balances. We believe that the change in energy intensity may be explained by the decreased use of coal halfway between the onset and at the end of the period, thus contributing to the explanation of this factor behavior in the industrial processing sector at least, especially in the latter years of our sample analyzed. So we may argue in favor of a substitution effect between fossil fuels that correctly capture the energy intensity effects as previously and initially expected.

In the European country group, the results show the opposite picture with their RP leading the emissions upwards while EF balancing them downwards for most years. [64] had already noticed larger differences observed among EU countries in terms of efficiency, as well as by [65]. The formers attribute these differences to different development levels, economic activity structure and to environmental awareness. Some of the European countries revealed, attending these authors results, a positive change in the fossil fuel energy component, above the average renewable capacity productivity. However, productivity capacity of renewable sources and internal financing in private changes are positive in all countries and periods except in Belgium, Denmark, Austria, Turkey and Norway. These findings reveal that richer countries will be intrinsically more willing to invest in renewable energy. The negative and inverse impact of renewables to GDP, the productivity inverse, supports [66] results to some extent. [66], claims that leading countries in renewable energy are less technically efficient than renewable energy stragglers placed among the most technically efficient European countries. Somehow, they respond as expected to renewable resources upsurges as noticed into the analysis of both financial internal investments in renewable capacity and the evolution of carbon emissions for the sub group of European countries here considered. 
The attained results also show that the effect between energy intensity and renewables productivity resources in electricity output is vital to shorten $\mathrm{CO}_{2}$ intensity of European countries. This especially in what concerns increasing energy efficiency and renewable resources use. These findings also show that countries with higher initial emission levels tend to reduce more emissions than those with lower initial levels. The cross effect of energy intensity change and of the productivity of renewables consumption on the decoupling progress, whose decoupling elasticity is greater than zero in most years and for most of the Top countries, even greater than one in some years, implies the promotion of the renewable energy effect on the decoupling between $\mathrm{CO}_{2}$ emissions and economic growth. This is mainly benefited from the carbon reduction effect, and it appears more significant in some countries considering those 5 years period changes, where it was observed the optimal state of strong decoupling.

Recent evidence as that in [67], use the explanation to justify the substantial drop in emissions of European countries, despite their lower GDP per capita level. But it turns harder to explain the situation of some European countries possessing current emission growths which are above the 1990 levels. This heterogeneous behavior was the key in some studies. Some authors stress for different economic growth rates, but it remains to be explained those situations not justified by the joint growth-convergence relationship. [64] tried to justify these findings through factors like technological change and the fossil fuel energy component changes. In this relative homogeneous European group of countries, at least subject to the same laws and environmental and economic laws, but still with different development levels and income highlighted differences, we can still find justifications for the noticed heterogeneity observed. Spanish and Italians underperformances were pointed by [64] and [65].

\section{Acknowledgments}

This research did not receive any specific grant from funding agencies in the public, commercial, or not-for-profit sectors. We kindly acknowledge the data provided, being available for public access, from World Development Indicators and from the US Energy Information Administration. We also thank to the two anonymous referees and the editor the useful comments, which helped us improving this work in the revision stage. 


\section{References}

[1] European Commission. European Commission: Taking stock of the Europe 2020 strategy for smart, sustainable and inclusive growth. COM 2014;130 final, Brussels, http://ec.europa.eu/eurostat/statisticsexplained/index.php/Europe_2020_indicators__climate_change_and_energy

[2] Inglesi-Lotz R, Blignaut J. South Africa's electricity consumption: a sectoral decomposition analysis. Appl Energ 2011;88:4779-84.

[3] Ang BW. The LMDI approach to decomposition analysis: a practical guide. Energy Policy 2005;33(7):867-71.

[4] Kopidou D, Tsakanikas A, Diakoulaki D. Common trends and drivers of CO2 emissions and employment: a decomposition analysis in the industrial sector of selected European Union countries. J Clean Prod 2016;112:4159-72.

[5] Markandya A, Pedroso-Galinato S, Streimikiene D. Energy intensity in transition economics: is there convergence towards the EU average. Energy Econ 2006;28:121-45.

[6] Andrade-Silva F, Guerra S. Analysis of the energy intensity evolution in the Brazilian industrial sector 1995-2005. Renew Sust Energ Rev 2009;13:2589-96.

[7] Sun J. Changes in energy consumption and energy intensity: a complete decomposition model. Energy Econ 1998;20:85-100.

[8] Korppoo AL, Vehmas J, Kinnunen M. What goes down must come up? Trends of industrial electricity use in the North-West of Russia. Energy Policy 2008;36:3588-97.

[9] Metcalf G. An empirical analysis of energy intensity of energy intensity and its determinants at the state level. Energy J 2008;29:1-27.

[10] Liddle B. Electricity intensity convergence in IEA/OECD countries: aggregate and sectoral analysis. Energy Policy 2009;37(4):1470-78.

[11] Mendiluce M, Perez-Arriaga I, Ocana C. Comparison of evolution of energy intensity in Spain and the EU15. Why is Spain different? Energy Policy 2010;38:639-45.

[12] Zhao X, Ma C, Hong D. Why did China's energy intensity increase during 1998e2006: decomposition and policy analysis? Energy Policy 2010;38:1379-88.

[13] Zhou N, Levine M, Price L. Overview of current energy efficiency policies in China. Energy Policy 2010;38:6439-52.

[14] Inglesi-Lotz R, Pouris A. Energy efficiency in South Africa: A decomposition exercise. Energy 2012;42:113-20.

[15] Winyuchakrit P, Limmeechokchai B. Trends of energy intensity and CO2 emissions in the Thai industrial sector: The decomposition analysis. Energy Sourc Part B: Econ, Plan Policy 2016;11:504-10.

[16] Ang BW, Choi KH. Decomposition of aggregate energy and gas emission intensities for industry: a refined Divisia index method. Energy J 1997;18:59-73. 
[17] Bhattacharyya SC, Matsumura W. Changes in GHG emission intensity in EU- 15: lessons from a decomposition analysis. Energy 2010;35:3315-22.

[18] Hammond GP, Norman JB. Decomposition analysis of energy-related carbon emissions from UK manufacturing. Energy 2011;41:220-27.

[19] Kumbaroglu G. A sectoral decomposition analysis of Turkish CO2 emissions over 1990e2007. Energy 2011; 36:2419-33.

[20] Sheinbaum C, Ruiz BJ, Ozawa L. Energy consumption and related CO2 emissions in five Latin American countries: changes from 1990 to 2006 and perspectives. Energy 2011;36:3629-38.

[21] Wang WW, Zhang M, Zhou M. Using LMDI method to analyze transport sector GHG emissions in China. Energy 2011;36:5909-15.

[22] Zhao M, Tan L, Zhang W, Ji M, Liu Y, Yu L. Decomposing the influencing factors of industrial carbon emissions in Shangai using the LMDI method. Energy 2010;35:2505-10.

[23] Cansino JM, Sanchez-Braza A, Rodriguez-Arevalo M. Driving forces of Spain's CO2 emissions: A LMDI decomposition approach. Renew Sust Energ Rev 2015;48:749-59.

[24] Shao S, Yang L, Gan C, Cao J, Geng Y, Guan D. Using and extended LMDI model to explore techno-economic drivers of energy-related industrial $\mathrm{CO} 2$ emissions changes: A case study for Shangai (China). Renew Sust Energ Rev 2016;55:516-36.

[25] Sumabat AK, Lopez NS, Yu KD, Hao H, Li R, Geng Y, Chiu ASF. Decomposition analysis of Philippine $\mathrm{CO} 2$ emissions from fuel combustion and electricity generation. Appl Energy 2016;164:795-804.

[26] Xu S-C, He Z-X, Long R-Y, Chen H, Han H-M, Zhang W-W. Comparative analysis of the regional contributions to carbon emissions in China. J Clean Prod 2016;127:406-17.

[27] Marrero GA, Ramos-Real FJ. Activity sectors and energy intensity decomposition analysis and policy implications for European countries (1991-2005). Energies 2013;6(5):2521-40.

[28] González FP, Landajo M, Presno MJ. The divisia real energy intensity indices evolution and attribution of percent changes in 20 European countries from 1995 to 2010. Energy 2013;58(1):340-9.

[29] González P F, Landajo M, Presno MJ. Tracking European Union CO2 emissions through LDMI (logarithmic mean divisia índex) decomposition. The activity Revaluation approach. Energy 2014;73:741-50.

[30] Obadi SM, Korček M. Investigation of Driving Forces of Energy Consumption in European Union 28 Countries. Int J Energ Econ Policy 2015;5(2):422-32.

[31] Karmellos M, Kopidou D, Diakoulaki D. A decomposition analysis of the driving factors of $\mathrm{CO} 2$ (carbon dioxide) emissions from the power sector in the European Union countries. Energy 2016;94:680-92. 
[32] O'Mahony T. Decomposition of Ireland's carbon emissions from 1990 to 2010: an extended Kaya identity. Energy Policy 2013;59:573-81.

[33] Xu SC, He ZX, Long RY. Factors that influence carbon emissions due to energy consumption in China: decomposition analysis using LMDI. Appl Energy 2014;127:18293.

[34] Zhang YJ, Da YB. The decomposition of energy-related carbon emission and its decoupling with economic growth in China. Renew Sust Energ Rev 2017;41:1255-66.

[35] Zhang X, Zhao X, Jiang Z, Shao S. How to achieve the 2030 CO2 emission-reduction targets for China's industrial sector: Retrospective decomposition and prospective trajectories. Global Environ Chang 2017;44:83-97.

[36] Chen S, Yan F, Wu R. Capital deepening, productivity promotion and CO2 emissions in China. Financ Trade Econ 2010;12:111-19.

[37] Zhao Y, Wang S, Zhang Z, Liu Y, Ahmad A. Driving factors of carbon emissions embodied in China-US trade: a structural decomposition analysis, J Cleaner Prod 2016;131:678-89. http://dx.doi.org/10.1016/j.jclepro.2016.04.114.

[38] Zang X, Zhao T, Wang J, Guo F. The effects of urbanization and household-related factors on residential direct CO2 emissions in Shanxi, China from 1995 to 2014: A decomposition analysis. Atmos Pollut Res 2017;8:297-309.

[39] Alves MR, Moutinho V. Decomposition analysis and innovative accounting approach for energy-related CO2 (carbon dioxide) emission intensity over 1996-2009 in Portugal. Energy 2013;57:775-87.

[40] Juntueng S, Towprayoon S, Chiarakorn S. Energy and carbon dioxide intensity of Thailand's steel industry and greenhouse gas emission projection toward the year 2050 . Resour Conserv Recycl 2014;87:46-56.

[41] Chen J, Cheng S, Song M. Decomposing inequality in energy-related CO2 emissions by source and source increment: The roles of production and residential consumption. Energy Policy 2017;http://dx.doi.org/10.1016/j.enpol.2017.05.003

[42] Wood R. Structural decomposition analysis of Australia's greenhouse gas emissions. Energy Policy 2009;37:4943-48.

[43] Shahiduzzaman MD, Layton A, Alam K. Decomposition of energy-related CO2 emissions in Australia: Challenges and policy implications. Econ Anal Policy 2015;45:10011 .

[44] De Freitas LC, Kaneko S. Decomposition of CO2 emissions change from energy consumption in Brazil: Challenges and policy implications. Energy Policy 2011;39:1495504.

[45] De Freitas LC, Kaneko S. Decomposing the decoupling of CO2 emissions and economic growth in Brazil. Ecol Econ 2011;70:1459-69. 
[46] Shahiduzzaman MD, Layton A. Changes in $\mathrm{CO} 2$ emissions over business cycle recessions and expansions in the United States: A decomposition analysis. Appl Energy 2015;150:25-35.

[47] Wang J-W, Liao H, Tang B-J, Ke R-Y, Wei Y-M. Is the CO2 emissions reduction from scale range, structural change or technology change? Evidence from non-metallic sector of 11 major economies in 1995-2009. J Clean Prod 2017;148:148-57.

[48] Jeong K, Kim S. LMDI decomposition analysis of greenhouse gas emissions in the Korean manufacturing sector. Energy Policy 2013;62:1245-53.

[49] Xu WQ, Li YJ, Xhu TY, Cao WJ. GHG emission in Iron and Steel making industry and its reduction prospect. Chin J Proc Eng 2013;13:175-80.

[50] Lin BQ, Wu Y, Zhang L. Estimates of the potential for energy conservation in the Chinese steel industry. Energy Policy 2011;39:3680-89.

[51] Liang R, Zhang L. Decoupling effects and rebound effects in the Chinese chemical sector from 1990 to 2008. Resour Science 2013;35:268-74.

[52] Lin B, Long H. Emissions reduction in China's chemical industry- Based on LMDI. Renew Sust Energ Rev 2016;53:1348-55.

[53] Wang M, Feng C. Decomposition of energy-related CO2 emissions in China: An empirical analysis based on provincial panel data of three sectors. Appl. Energy 2017;190:772-87. https://doi.org/10.1016/j.apenergy.2017.01.007.

[54] Sbia R, Shahbaz M, Ozturk I. Economic growth, financial development, urbanisation and electricity consumption nexus in UAE. J Econ Res 2017;30(1):527-49. http://dx.doi.org/10.1080/1331677X.2017.1305792

[55] Kander A, Lindmark M. Foreign trade and declining pollution in Sweden: a decomposition analysis of long-term structural and technological effects. Energy Policy 2006;34:1590-1599 https://doi.org/10.1016/j.enpol.2004.12.007.

[56] Kopidou D, Diakoulaki D. Decomposing industrial CO2 emissions of Southern European countries into production- and consumption-based driving factors. J Cleaner Prod 2017; Online. https://doi.org/10.1016/j.jclepro.2017.05.183.

[57] Henriques ST, Kander A. The modest environmental relief resulting from the transition to a service economy. Ecol. Econ. 2010;70:271-282. https://doi.org/10.1016/j.ecolecon.2010.08.010.

[58] Voigt S, De Cian E, Schymura M, Verdolini E. Energy intensity developments in 40 major economies: structural change or technology improvement? Energy Econ. 2014;41:4762. https://doi.org/10.1016/j.eneco.2013.10.015

[59] Kopidou D, Tsakanikas A, Diakoulaki D. Common trends and drivers of CO2 emissions and employment: a decomposition analysis in the industrial sector of selected European Union countries. J. Clean. Prod. 2016;112:4159-72. https://doi.org/10.1016/j.jclepro.2015.06.079 
[60] Shahbaz, M., Nasreen, S., Ozturk, I. FDI, Growth and CO2 Emissions Relationship: Evidence from High, Middle and Low Income Countries. Bull Energ Econ (BEE), The Economics and Social Development Organization (TESDO) 2016;4(1):54-69.

[61] Voigt S, De Cian E, Schymura M, Verdolini E. Energy Intensity Developments in 40 Major Economies: Structural Change or Technology Improvement? Energ Econ 2011;41:4762.

[62] Dogan E, Seker F. The influence of real output, renewable and non-renewable energy, trade and financial development on carbon emissions in the top renewable energy countries. Renew Sust Energ Rev 2016;60:1074-85.

[63] Tapio P. Towards a theory of decoupling: Degrees of decoupling in the EU and the case of road traffic in Finland between 1970 and 2001. Transp. Policy 2005;12:137-51.

[64] Camarero M, Castillo-Giménez J, Picazo-Tadeo A, Tamarit C. Is eco-efficiency in greenhouse gas emissions converging among European Union countries? Empir Econ 2014;47(1):143-68.

[65] Picazo-Tadeo AJ, Castillo-Giménez J, Beltrán-Esteve M. An intertemporal approach to measuring environmental performance with directional distance functions: Greenhouse gas emissions in the European Union. Ecol Econ 2014;100(C):173-82.

[66] Menegaki AN. Growth and renewable energy in Europe: a random effect model with evidence for neutrality hypothesis. Energ Econ 2011;33:257-63.

[67] Moutinho V, Madaleno M, Silva PM. Which factors drive CO2 emissions in EU-15? Decomposition and innovative accounting. Energ Eff 2016;9(5):1087-113. 


\section{Appendix}

Table A.1 - Effects decomposition contributions to $\mathrm{CO}_{2}$ emission changes for the set of the Top 23 Renewable countries

\begin{tabular}{|c|c|c|c|c|c|c|c|c|}
\hline Year & Var CO2 & $\overline{C I}$ & $\mathrm{TF}$ & FI & $\mathrm{RP}$ & $\overline{E F}$ & $\mathrm{Fd}$ & TOTAL \\
\hline 1986 & 0.938 & 12.441 & -26.728 & 14.026 & -18.340 & 13.686 & 5.916 & $100 \%$ \\
\hline 1987 & 1.090 & 0.527 & 4.828 & -5.036 & -36.203 & 34.493 & 2.391 & $100 \%$ \\
\hline 1988 & 0.364 & -13.823 & -2.999 & 15.800 & 9.538 & -20.626 & 13.109 & $100 \%$ \\
\hline 1989 & -47.921 & 0.052 & 0.391 & -0.457 & 0.547 & 0.635 & -0.167 & $100 \%$ \\
\hline 1990 & 38.781 & -0.101 & 0.103 & -0.025 & -1.708 & 2.738 & -0.008 & $100 \%$ \\
\hline 1991 & 0.373 & 7.653 & -42.156 & 34.645 & -54.211 & 56.199 & -1.130 & $100 \%$ \\
\hline 1992 & 0.109 & -10.409 & 26.048 & -17.617 & -648.610 & 547.302 & 104.286 & $100 \%$ \\
\hline 1993 & 0.461 & -0.996 & 4.784 & -3.506 & -33.640 & 27.924 & 6.435 & $100 \%$ \\
\hline 1994 & 0.471 & -12.801 & 33.523 & -20.982 & 5.870 & -1.156 & -3.453 & $100 \%$ \\
\hline 1995 & 0.762 & -8.490 & -6.205 & 14.912 & -49.123 & 46.825 & 3.081 & $100 \%$ \\
\hline 1996 & 1.266 & -0.677 & -4.144 & 5.365 & 19.593 & -21.201 & 2.065 & $100 \%$ \\
\hline 1997 & 0.255 & -22.395 & 60.652 & -39.758 & -15.168 & -19.524 & 37.193 & $100 \%$ \\
\hline 1998 & 7.634 & -0.048 & -0.160 & 0.264 & 3.892 & -2.419 & -0.529 & $100 \%$ \\
\hline 1999 & 0.554 & 1.235 & -23.375 & 21.989 & -85.758 & 94.884 & -7.975 & $100 \%$ \\
\hline 2000 & 0.139 & -68.066 & -42.175 & 106.645 & -183.402 & 170.842 & 17.157 & $100 \%$ \\
\hline 2001 & -0.074 & 9.013 & -146.765 & 142.901 & 379.791 & -334.624 & -49.315 & $100 \%$ \\
\hline 2002 & 0.001 & 2120.537 & -33126.281 & 30735.324 & -348.938 & -396.650 & 1017.008 & $100 \%$ \\
\hline 2003 & 0.285 & 4.810 & -119.333 & 114.267 & 0.795 & -1.830 & 2.292 & $100 \%$ \\
\hline 2004 & -38.779 & 0.124 & 0.138 & -0.260 & 1.318 & -0.230 & -0.091 & $100 \%$ \\
\hline 2005 & 0.406 & -9.036 & -9.833 & 18.542 & -118.691 & 104.086 & 15.932 & $100 \%$ \\
\hline 2006 & 0.017 & -220.691 & 265.045 & -78.769 & -983.297 & 701.769 & 316.943 & $100 \%$ \\
\hline 2007 & 0.423 & -2.696 & 55.457 & -53.184 & -87.553 & 77.762 & 11.214 & $100 \%$ \\
\hline 2008 & -0.054 & 66.345 & 601.069 & -661.685 & 357.855 & -277.011 & -85.573 & $100 \%$ \\
\hline 2009 & -0.707 & -22.656 & 25.759 & -2.620 & 29.665 & -24.897 & -4.251 & $100 \%$ \\
\hline 2010 & 0.904 & -7.915 & -2.648 & 10.866 & -14.887 & 13.223 & 2.361 & $100 \%$ \\
\hline 2011 & -0.573 & 13.947 & -24.268 & 12.091 & 35.635 & -31.052 & -5.353 & $100 \%$ \\
\hline
\end{tabular}

Note: CI denotes carbon trade intensity over $\triangle \mathrm{CO} 2$, TF the trade of fossil fuels effect over $\Delta \mathrm{CO}$, FI fossil fuels intensity over $\Delta \mathrm{CO} 2$, RP renewable sources productivity contribution to $\mathrm{CO} 2(\triangle \mathrm{RP} / \Delta \mathrm{CO} 2), \mathrm{EF}$ electricity financial power effect over $\Delta \mathrm{CO} 2, \mathrm{Fd}$ the financial development effect over $\Delta \mathrm{CO} 2$; $\mathrm{Var} \mathrm{CO} 2$ stands for $\mathrm{CO} 2$ emission changes between $\mathrm{t}$ and $\mathrm{t}-1$ due to the six considered effects by years. 
Table A.2 - Effects decomposition contributions to $\mathrm{CO}_{2}$ emission changes for the set of the European Top 23 Renewable countries

\begin{tabular}{|c|c|c|c|c|c|c|c|c|}
\hline Year & Var CO2 & $\mathrm{CI}$ & TF & FI & $\mathrm{RP}$ & $\mathrm{EF}$ & $\mathrm{Fd}$ & TOTAL \\
\hline 1986 & 0.623 & 10.709 & -5.715 & -5.363 & -14.990 & 9.468 & 6.892 & $100 \%$ \\
\hline 1987 & 0.352 & -0.909 & 13.903 & -13.090 & -72.506 & 70.168 & 3.434 & $100 \%$ \\
\hline 1988 & -0.047 & 38.515 & -108.061 & 80.228 & 218.526 & -183.360 & -44.848 & $100 \%$ \\
\hline 1989 & -48.445 & 0.032 & 0.194 & -0.235 & 0.378 & 0.678 & -0.047 & $100 \%$ \\
\hline 1990 & -0.150 & -5.069 & 61.596 & -52.568 & 395.152 & -387.730 & -10.381 & $100 \%$ \\
\hline 1991 & 0.503 & 3.978 & -26.598 & 23.350 & -47.265 & 47.532 & 0.002 & $100 \%$ \\
\hline 1992 & -0.208 & -1.095 & 3.596 & -0.854 & 97.048 & -78.644 & -19.051 & $100 \%$ \\
\hline 1993 & 0.011 & -61.277 & 317.748 & -259.880 & -1596.550 & 1690.492 & -89.533 & $100 \%$ \\
\hline 1994 & 0.119 & -34.353 & 64.424 & -30.793 & 64.661 & -44.509 & -18.431 & $100 \%$ \\
\hline 1995 & 0.308 & -9.148 & 3.264 & 5.960 & -109.140 & 104.070 & 5.995 & $100 \%$ \\
\hline 1996 & 0.515 & -1.228 & 0.688 & 1.071 & -0.859 & -3.695 & 5.023 & $100 \%$ \\
\hline 1997 & -0.128 & 26.555 & -35.050 & 11.830 & 115.269 & -94.833 & -22.771 & $100 \%$ \\
\hline 1998 & 0.339 & 3.282 & -15.463 & 12.395 & -18.130 & 21.812 & -2.895 & $100 \%$ \\
\hline 1999 & 0.059 & -0.876 & 35.282 & -37.369 & 229.257 & -243.861 & 18.567 & $100 \%$ \\
\hline 2000 & -0.029 & 188.371 & -11.397 & -164.072 & 127.146 & -2.759 & -136.289 & $100 \%$ \\
\hline 2001 & 0.151 & -0.736 & -5.263 & 6.341 & -37.649 & 15.746 & 22.562 & $100 \%$ \\
\hline 2002 & 0.119 & 16.941 & -51.486 & 34.338 & 66.251 & -68.228 & 3.185 & $100 \%$ \\
\hline 2003 & 0.381 & 4.768 & -2.255 & -1.847 & 15.147 & -16.820 & 2.007 & $100 \%$ \\
\hline 2004 & -39.315 & 0.049 & -0.234 & 0.191 & 1.179 & -0.119 & -0.066 & $100 \%$ \\
\hline 2005 & -0.020 & 91.141 & -226.428 & 147.395 & 1748.160 & -1531.719 & -227.549 & $100 \%$ \\
\hline 2006 & 0.040 & -75.691 & 186.299 & -116.583 & -582.012 & 500.368 & 88.620 & $100 \%$ \\
\hline 2007 & -0.064 & 12.911 & -439.917 & 431.746 & 222.762 & -185.997 & -40.505 & $100 \%$ \\
\hline 2008 & -0.166 & 9.492 & 148.043 & -156.357 & 78.564 & -66.069 & -12.674 & $100 \%$ \\
\hline 2009 & -0.667 & -10.069 & 11.940 & -1.354 & 20.975 & -18.605 & -1.888 & $100 \%$ \\
\hline 2010 & 0.465 & -8.608 & -10.432 & 19.599 & -25.801 & 24.583 & 1.659 & $100 \%$ \\
\hline 2011 & -0.694 & 6.732 & -21.614 & 16.098 & 15.023 & -14.924 & -0.315 & $100 \%$ \\
\hline
\end{tabular}

Note: CI denotes carbon trade intensity over $\Delta \mathrm{CO} 2$, TF the trade of fossil fuels effect over $\Delta \mathrm{CO} 2$, FI fossil fuels intensity over $\Delta \mathrm{CO} 2, \mathrm{RP}$ renewable sources productivity contribution to $\mathrm{CO} 2(\Delta \mathrm{RP} / \Delta \mathrm{CO} 2)$, EF electricity financial power effect over $\Delta \mathrm{CO} 2, \mathrm{Fd}$ the financial development effect over $\Delta \mathrm{CO} 2$; Var $\mathrm{CO} 2$ stands for $\mathrm{CO} 2$ emission changes between $\mathrm{t}$ and $\mathrm{t}-1$ due to the six considered effects by years. 
Table A.3 - Effects decomposition contributions to $\mathrm{CO}_{2}$ emission changes for the set of the Rest of the World Top 23 Renewable countries

\begin{tabular}{|c|c|c|c|c|c|c|c|c|}
\hline Year & Var CO2 & CI & $\mathrm{TF}$ & FI & $\mathrm{RP}$ & $\mathrm{EF}$ & $\mathrm{Fd}$ & TOTAL \\
\hline 1986 & 0.315 & 15.862 & -68.238 & 52.326 & -24.958 & 22.019 & 3.989 & $100 \%$ \\
\hline 1987 & 0.738 & 1.211 & 0.505 & -1.199 & -18.911 & 17.500 & 1.894 & $100 \%$ \\
\hline 1988 & 0.411 & -7.800 & -15.088 & 23.214 & 33.585 & -39.351 & 6.440 & $100 \%$ \\
\hline 1989 & 0.524 & -1.815 & -17.789 & 20.066 & -15.058 & 4.640 & 10.955 & $100 \%$ \\
\hline 1990 & 38.931 & -0.120 & 0.340 & -0.228 & -0.177 & 1.232 & -0.048 & $100 \%$ \\
\hline 1991 & -0.130 & -6.587 & 18.131 & -9.121 & -27.297 & 22.616 & 3.258 & $100 \%$ \\
\hline 1992 & 0.317 & -4.300 & 11.320 & -6.621 & -159.492 & 136.710 & 23.382 & $100 \%$ \\
\hline 1993 & 0.450 & 0.478 & -2.871 & 2.765 & 4.590 & -12.744 & 8.782 & $100 \%$ \\
\hline 1994 & 0.352 & -5.552 & 23.130 & -17.682 & -13.905 & 13.426 & 1.585 & $100 \%$ \\
\hline 1995 & 0.453 & -8.043 & -12.647 & 21.003 & -8.287 & 7.875 & 1.099 & $100 \%$ \\
\hline 1996 & 0.750 & -0.299 & -7.464 & 8.315 & 33.645 & -33.230 & 0.032 & $100 \%$ \\
\hline 1997 & 0.383 & -6.010 & 28.618 & -22.490 & 28.493 & -44.732 & 17.121 & $100 \%$ \\
\hline 1998 & 7.295 & -0.203 & 0.551 & -0.300 & 4.916 & -3.546 & -0.419 & $100 \%$ \\
\hline 1999 & 0.496 & 1.485 & -30.322 & 29.019 & -123.067 & 135.003 & -11.118 & $100 \%$ \\
\hline 2000 & 0.168 & -24.232 & -36.914 & 60.370 & -130.318 & 141.167 & -9.072 & $100 \%$ \\
\hline 2001 & -0.225 & 2.471 & -51.806 & 51.258 & 99.656 & -99.498 & -1.080 & $100 \%$ \\
\hline 2002 & -0.117 & -5.496 & 301.285 & -293.115 & 70.679 & -64.725 & -7.629 & $100 \%$ \\
\hline 2003 & -0.095 & 4.643 & 347.629 & -348.849 & 58.039 & -61.619 & 1.157 & $100 \%$ \\
\hline 2004 & 0.536 & -5.370 & -27.127 & 32.830 & -8.916 & 7.848 & 1.735 & $100 \%$ \\
\hline 2005 & 0.426 & -4.352 & -19.960 & 24.567 & -31.402 & 27.600 & 4.547 & $100 \%$ \\
\hline 2006 & -0.022 & 35.648 & 125.833 & -145.619 & -273.883 & 345.721 & -86.700 & $100 \%$ \\
\hline 2007 & 0.487 & -0.647 & -9.582 & 10.484 & -46.811 & 43.133 & 4.424 & $100 \%$ \\
\hline 2008 & 0.111 & -18.397 & -74.189 & 91.532 & -58.442 & 37.409 & 23.087 & $100 \%$ \\
\hline 2009 & -0.040 & -231.431 & 254.971 & -23.619 & 173.790 & -129.262 & -43.449 & $100 \%$ \\
\hline 2010 & 0.439 & -7.182 & 5.594 & 1.620 & -3.331 & 1.194 & 3.105 & $100 \%$ \\
\hline 2011 & 0.121 & -27.320 & -9.085 & 35.008 & -82.261 & 61.193 & 23.465 & $100 \%$ \\
\hline
\end{tabular}

Note: $C$ I denotes carbon trade intensity over $\triangle \mathrm{CO} 2$, TF the trade of fossil fuels effect over $\Delta \mathrm{CO} 2$, FI fossil fuels intensity over $\Delta \mathrm{CO} 2, \mathrm{RP}$ renewable sources productivity contribution to $\mathrm{CO} 2(\Delta \mathrm{RP} / \Delta \mathrm{CO} 2)$, EF electricity financial power effect over $\Delta \mathrm{CO} 2, \mathrm{Fd}$ the financial development effect over $\Delta \mathrm{CO} 2$; Var $\mathrm{CO} 2$ stands for $\mathrm{CO} 2$ emission changes between $\mathrm{t}$ and $\mathrm{t}-1$ due to the six considered effects by years. 
Table A.4 - Tapio Decomposition index (DI), percentage change of GDP, percentage change of $\mathrm{CO}_{2}$ and percentage of non-renewable energy consumption (NREC) and renewable energy consumption (REC): 1986-1994; 1995-2004; 2005-2011.

\begin{tabular}{|c|c|c|c|c|c|c|c|c|c|c|c|c|c|c|c|c|c|c|}
\hline & & $\%$ GDP & $\% \mathrm{CO}_{2}$ & $\%$ NREC & $\%$ REC & DI & & $\%$ GDP & $\% \mathrm{CO}_{2}$ & $\%$ NREC & $\%$ REC & DI & & $\%$ GDP & $\% \mathrm{CO}_{2}$ & \%NREC & $\%$ REC & DI \\
\hline 1986-1994 & Australia & 0.0011 & 0.0008 & 0.0089 & -0.0314 & 0.7201 & 1995-2004 & 0.0015 & 0.0012 & 0.0080 & 0.9844 & 0.7731 & $2005-2011$ & 0.0010 & 0.0005 & 0.0012 & 0.1441 & 0.5285 \\
\hline 1986-1994 & Austria & 0.0010 & 0.0003 & 0.0082 & -0.5121 & 0.2733 & 1995-2004 & 0.0010 & 0.0015 & 0.0147 & 0.4378 & 1.4452 & $2005-2011$ & 0.0006 & -0.0008 & $\begin{array}{l}-0.0019 \\
\end{array}$ & 0.0886 & -1.2654 \\
\hline 1986-1994 & Belgium & 0.0009 & 0.0004 & 0.0118 & -0.0717 & 0.4999 & 1995-2004 & 0.0010 & -0.0001 & 0.0055 & -0.4251 & -0.0759 & $2005-2011$ & 0.0005 & -0.0010 & -0.0041 & 0.8028 & -1.8503 \\
\hline 1986-1994 & Brazil & 0.0009 & 0.0017 & 0.0208 & 0.0487 & 1.9779 & 1995-2004 & 0.0010 & 0.0019 & 0.0487 & 0.0469 & 1.8801 & $2005-2011$ & 0.0014 & 0.0019 & 0.0166 & 0.0511 & 1.3350 \\
\hline 1986-1994 & Canada & 0.0008 & 0.0004 & 0.0045 & 0.1561 & 0.5773 & 1995-2004 & 0.0013 & 0.0011 & 0.0081 & 0.0301 & 0.8190 & $2005-2011$ & \begin{tabular}{|l|}
0.8578 \\
\end{tabular} & -0.0009 & $\begin{array}{l}-0.0018 \\
\end{array}$ & 0.0406 & -0.0011 \\
\hline 1986-1994 & Chile & 0.0029 & 0.0037 & 0.0580 & 0.7498 & 1.2881 & $1995-2004$ & 0.0020 & 0.0029 & 0.0774 & -1.3816 & 1.4290 & $2005-2011$ & 0.0016 & 0.0022 & 0.0166 & 0.3012 & 1.4083 \\
\hline 1986-1994 & Denmark & 0.0007 & 0.0001 & 0.0124 & 0.5655 & 0.1597 & 1995-2004 & 0.0009 & -0.0011 & -0.0061 & 0.1167 & -1.2167 & $2005-2011$ & 0.0002 & -0.0018 & -0.0165 & 0.0230 & -8.8334 \\
\hline 1986-1994 & France & 0.0008 & -0.0010 & -0.0137 & 0.0251 & -1.1536 & $1995-2004$ & 0.0009 & 0.0008 & 0.0157 & 0.0135 & 0.8682 & $2005-2011$ & 0.0004 & -0.0010 & $\begin{array}{l}-0.0058 \\
\end{array}$ & 0.0331 & -2.6254 \\
\hline 1986-1994 & Indonesia & 0.0028 & 0.0035 & 0.0254 & 0.0818 & 1.2770 & $1995-2004$ & 0.0012 & 0.0024 & 0.0187 & 0.0292 & 1.9672 & $2005-2011$ & -0.0061 & 0.0037 & 0.0132 & 0.0075 & $\begin{array}{l}-0.6077 \\
\end{array}$ \\
\hline 1986-1994 & Italy & 0.0008 & 0.0005 & 0.0073 & -0.0030 & 0.6745 & $1995-2004$ & 0.0007 & 0.0008 & 0.0060 & 0.0243 & 1.3012 & $2005-2011$ & 0.0000 & -0.0013 & $\begin{array}{l}-0.0029 \\
\end{array}$ & 0.0397 & 10.03 \\
\hline 1986-1994 & Japan & 0.0011 & 0.0013 & 0.0070 & $\begin{array}{l}-0.0002 \\
\end{array}$ & 1.1740 & 1995-2004 & 0.0004 & 0.0004 & 0.0014 & 0.0089 & 0.9096 & $2005-2011$ & 0.0001 & $\begin{array}{l}-0.0004 \\
\end{array}$ & 0.0043 & 0.0099 & -3.2323 \\
\hline 1986-1994 & Kenya & 0.0015 & 0.0040 & 0.1396 & 0.0373 & 2.7054 & $1995-2004$ & 0.0013 & 0.0011 & -0.0426 & 0.0306 & 0.8614 & $2005-2011$ & 0.0022 & 0.0051 & 0.2558 & 0.0057 & 2.3564 \\
\hline 1986-1994 & Mexico & 0.0010 & 0.0011 & 0.0133 & 0.0328 & 1.0634 & 1995-2004 & 0.0010 & 0.0009 & 0.0108 & -0.0001 & 0.9671 & $2005-2011$ & 0.0009 & 0.0009 & 0.0063 & 0.0053 & 1.0493 \\
\hline 1986-1994 & Netherlands & 0.0010 & 0.0007 & 0.0061 & 0.0844 & 0.6399 & 1995-2004 & 0.0011 & 0.0004 & 0.0056 & 0.0749 & 0.3566 & $2005-2011$ & 0.8577 & -0.0004 & 0.0010 & 0.0432 & -0.0004 \\
\hline 1986-1994 & Norway & 0.0010 & -0.0012 & 0.0484 & -0.0171 & -1.2247 & 1995-2004 & 0.0013 & 0.0021 & -0.0039 & 0.0253 & 1.6537 & $2005-2011$ & \begin{tabular}{|l|}
0.0004 \\
\end{tabular} & 0.0005 & -0.1701 & 0.0312 & 1.3200 \\
\hline 1986-1994 & Peru & 0.0004 & 0.0012 & -0.0362 & -0.0148 & 2.9923 & 1995-2004 & 0.0016 & 0.0021 & 0.1955 & 0.0095 & 1.3276 & $2005-2011$ & 0.0026 & 0.0042 & 0.0614 & 0.0665 & 1.6124 \\
\hline 1986-1994 & Philippines & 0.0013 & 0.0043 & 0.0170 & -0.0007 & 3.2461 & $1995-2004$ & 0.0018 & 0.0019 & 0.0256 & 0.0066 & 1.0591 & $2005-2011$ & 0.0018 & 0.0008 & 0.0113 & -0.0042 & 0.4444 \\
\hline 1986-1994 & Portugal & 0.0014 & 0.0035 & 0.0499 & 0.0125 & 2.5523 & 1995-2004 & 0.0012 & 0.0018 & 0.0193 & 0.0231 & 1.4899 & $2005-2011$ & 0.0001 & -0.0019 & $\begin{array}{l}-0.0063 \\
\end{array}$ & 0.0632 & -17.6111 \\
\hline 1986-1994 & Spain & 0.0011 & 0.0009 & 0.0030 & 0.0132 & 0.7911 & $1995-2004$ & 0.0014 & 0.0021 & 0.0182 & 0.0661 & 1.4851 & $2005-2011$ & 0.0004 & -0.0017 & -0.0025 & 0.0260 & -3.8573 \\
\hline 1986-1994 & Sweden & 0.0005 & -0.0008 & 0.0214 & 0.0047 & -1.6368 & 1995-2004 & 0.0013 & 0.0000 & -0.0108 & 0.0249 & -0.0286 & $2005-2011$ & 0.0007 & -0.0003 & 0.0061 & 0.0160 & -0.4869 \\
\hline 1986-1994 & Turkey & 0.0015 & 0.0023 & 0.0241 & 0.2602 & 1.5241 & 1995-2004 & 0.0017 & 0.0021 & 0.0212 & 0.0391 & 1.2194 & $2005-2011$ & 0.0017 & 0.0026 & 0.0149 & 0.1588 & 1.5262 \\
\hline 1986-1994 & United Kingdom & 0.0009 & -0.0001 & -0.0005 & -0.3018 & -0.1445 & 1995-2004 & 0.0012 & -0.0001 & 0.0055 & 0.0351 & -0.0646 & $2005-2011$ & 0.0004 & -0.0013 & -0.0033 & 0.0314 & -3.7028 \\
\hline 1986-1994 & United States & 0.0010 & 0.0006 & 0.0034 & 0.0374 & 0.6324 & 1995-2004 & 0.0012 & 0.0006 & 0.0031 & 0.0020 & 0.4966 & $2005-2011$ & 0.0004 & -0.0005 & -0.0002 & 0.0168 & -1.2893 \\
\hline
\end{tabular}


Table A.5 - Different States of Decoupling by [63] (Tapio, 2005)

\begin{tabular}{|c|c|c|c|c|}
\hline $\begin{array}{c}\text { Environmental } \\
\text { Pressure }\end{array}$ & $\begin{array}{l}\text { Economic } \\
\text { Growth }\end{array}$ & Elasticity: $\gamma$ & State & \\
\hline$\Delta \mathrm{CO} 2>0$ & $\Delta \mathrm{GDP}>0$ & $\gamma>1.2$ & \multirow{3}{*}{$\begin{array}{c}\text { Negative } \\
\text { Decoupling }\end{array}$} & $\begin{array}{c}\text { Expansionary Negative } \\
\text { Decoupling }\end{array}$ \\
\hline$\Delta \mathrm{CO} 2>0$ & $\Delta$ GDP $<0$ & $\gamma<0$ & & Strong Negative Decoupling \\
\hline$\Delta \mathrm{CO} 2<0$ & $\Delta \mathrm{GDP}<0$ & $0 \leq y \leq 0.8$ & & Weak Negative Decoupling \\
\hline$\Delta \mathrm{CO} 2>0$ & $\Delta \mathrm{GDP}>0$ & $0 \leq \mathrm{Y} \leq 0.8$ & \multirow{3}{*}{ Decoupling } & Weak Decoupling \\
\hline$\Delta \mathrm{CO} 2<0$ & $\Delta \mathrm{GDP}>0$ & $\gamma<0$ & & Strong Decoupling \\
\hline$\Delta \mathrm{CO} 2<0$ & $\Delta \mathrm{GDP}<0$ & $\gamma>1.2$ & & Recession Decoupling \\
\hline$\Delta \mathrm{CO} 2>0$ & $\Delta \mathrm{GDP}>0$ & $0.8 \leq \gamma \leq 1.2$ & \multirow[b]{2}{*}{ Link } & Growing Link \\
\hline$\Delta \mathrm{CO} 2<0$ & $\Delta \mathrm{GDP}<0$ & $0.8 \leq \gamma \leq 1.2$ & & Recession Link \\
\hline
\end{tabular}

Figure A.1 - Decoupling index and percentage of renewables by country considering the year changes: 1986 to 1994

$$
\text { DI (86-94) — — Renew (86-94) }
$$

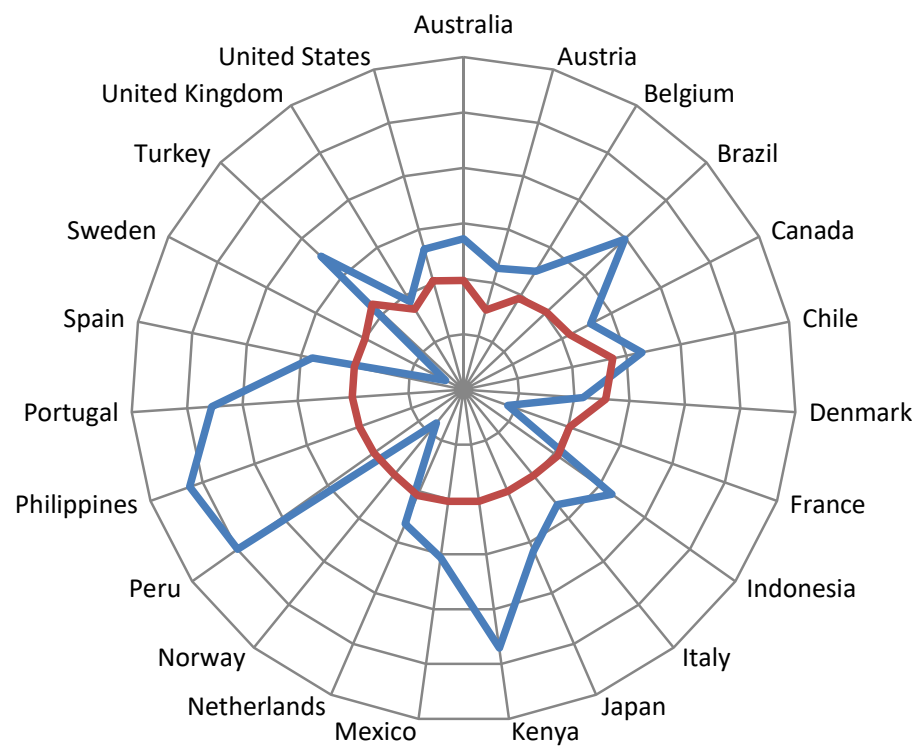


Figure A.2 - Decoupling index and percentage of renewables by country considering the year changes: 1995 to 2004

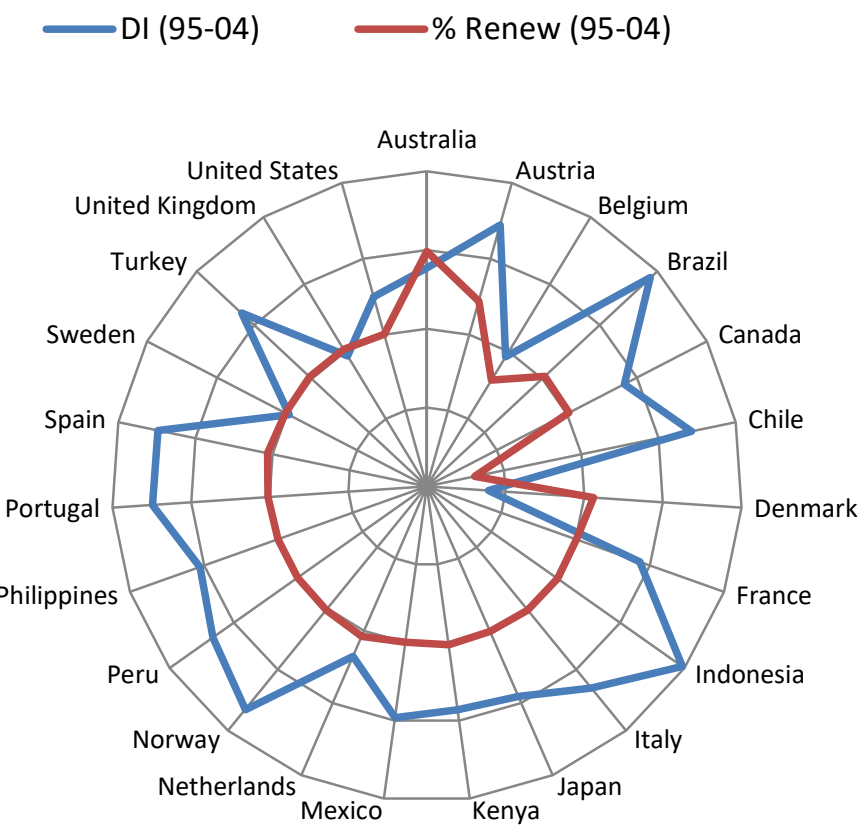

Figure A.3 - Decoupling index and percentage of renewables by country considering the year changes: 2005 to 2011
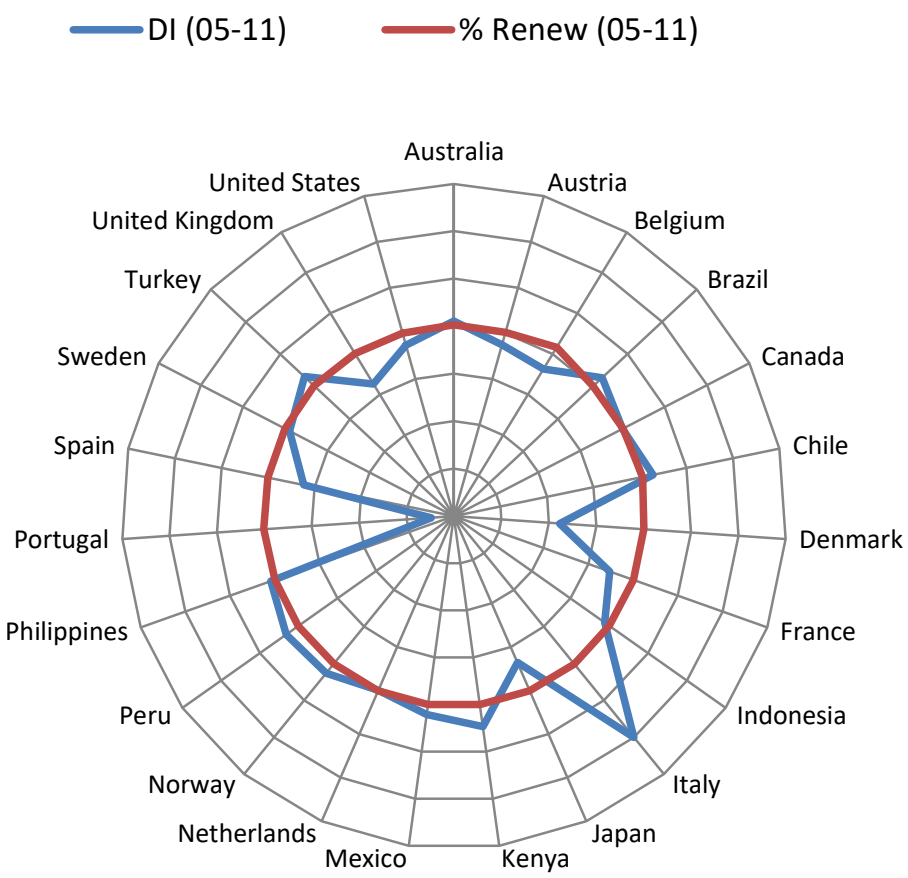